\title{
Mechanical Properties of Crumb Rubber Mortar Containing Nano-Silica Using Response Surface Methodology
}

\author{
Syafiqah Shahrul ${ }^{(0)}$, Bashar S. Mohammed ${ }^{*}$, M. M. A. Wahab and M. S. Liew \\ Civil and Environmental Engineering Department, Faculty of Engineering, Universiti Teknologi \\ PETRONAS (UTP), Bandar Seri Iskandar 32610, Perak, Malaysia; syafiqah_18001894@utp.edu.my (S.S.); \\ mubarakwahab@utp.edu.my (M.M.A.W.); shahir_liew@utp.edu.my (M.S.L.) \\ * Correspondence: bashar.mohammed@utp.edu.my
}

check for updates

Citation: Shahrul, S.; Mohammed, B.S.; Wahab, M.M.A.; Liew, M.S. Mechanical Properties of Crumb Rubber Mortar Containing

Nano-Silica Using Response Surface Methodology. Materials 2021, 14, 5496. https://doi.org/10.3390/

ma14195496

Academic Editor: Miguel Angel Garcia Aranda

Received: 7 July 2021

Accepted: 24 August 2021

Published: 23 September 2021

Publisher's Note: MDPI stays neutral with regard to jurisdictional claims in published maps and institutional affiliations.

Copyright: (C) 2021 by the authors. Licensee MDPI, Basel, Switzerland. This article is an open access article distributed under the terms and conditions of the Creative Commons Attribution (CC BY) license (https:/ / creativecommons.org/licenses/by/ $4.0 /)$.

\begin{abstract}
Crumb rubber (CR) from scrap tires is used as a partial replacement of fine aggregates in cement paste. This promotes the sustainable development of the environment, economy, and society, as waste tires are non-biodegradable and flammable. They occupy large landfill areas and are breeding grounds for mosquitoes and rodents. Inclusion of CR in mortar leads to several improvements on the mixture properties such as ductility, toughness, and impact resistance. However, it exhibits lower strengths and Modulus of Elasticity (ME). Therefore, to promote the use of mortar containing CR, it is vital to improve its mechanical strength. Past studies proved that nano-silica (NS) improves the strength of concrete due to the physico-chemical effects of NS. This study aims to examine the mechanical properties of crumb rubber mortar containing nano-silica (NS-CRM) and to develop models to predict these properties using Response Surface Methodology (RSM). Two variables were considered, CR as partial replacement to sand by volume $(0 \%, 7.5 \%, 15 \%)$, and NS as partial replacement to cement by weight $(0 \%, 2.5 \%, 5 \%)$. The results demonstrated a significant improvement in the mechanical properties of CRM when incorporating NS, and the models developed using RSM were acceptable with a $2 \%$ to $3 \%$ variation.
\end{abstract}

Keywords: crumb rubber; nano-silica; mortar; response surface methodology; scrap tires; recycling

\section{Introduction}

As the world's population grows, so does the need for automobiles, especially in urban areas [1]. It is reported that five billion scrap tires are destined for landfills by 2030 [2]. Scrap tires are flammable and non-biodegradable, due to the presence of stabilizers, additives, and the cross-linked structure of the elastomeric polymer material [3], and they pose serious environmental, health, and aesthetic problems globally. They are bulky and require a large area in landfills. Due to their convex shape, they provide excellent breeding grounds for mosquitoes and rodents.

Reuse of scrap tires in construction will contribute to environment-friendly solutions for scrap tire disposal problems. Use of scrap tires in the form of crump rubber (CR) helps in improving the properties of the construction materials such as energy absorption [4], sound absorption [5,6], ductility [7], fatigue performance [8], impact resistance [9,10], electrical resistivity [11], heat resistivity [12], toughness [13], and post-crack strength [14]. Extensive research works conducted on concrete containing-CR as partial replacement to fine aggregate are well documented. However, research works on mortar containing CR are scarce and very limited.

Wongsa et al. [15] did a study on the mechanical properties of mortar by replacing sand with CR at $100 \%$ by volume. They reported that the density, thermal conductivity, compressive strength, and flexural strength of crumb rubber mortar (CRM) decrease as the percentage of CR increases. This is attributed to the weak bonding between CR and cement matrix, as well as the lower Modulus of Elasticity (ME) of the CR as compared to sand. However, a 100\% replacement of sand by CR results in changing the failure 
mode of the mortar from brittle to ductile. It is suggested that CRM can be used for making environmentally friendly and lightweight bricks and blocks with improved thermal insulation. Yu and Zhu [16] investigated the properties of mortar by partially replacing sand with CR from $0 \%$ to $50 \%$ by volume. They concluded that the CRM exhibits reduction in ME, drying shrinkage, compressive strength, flexural strength, and splitting strength when the size of $C R$ decreases, and the volume of $C R$ increases. A strong relationship exists between the mechanical strengths and the porosity of the CRM. The mesopores volume of CRM increases as the percentage of CR increases. This is attributed to the hydrophobic nature of $C R$ as it repels water and entraps air on its surface, which consequently increases the size of the pores in the hardened CRM. Angelin et al. [17] have studied the properties of mortar by partially replacing sand with CR from $0 \%$ to $30 \%$ by weight. The results indicated that the slump flow decreases as the percentage of CR increases. This reduction is caused by the increasing friction produced between the CR particles and cement paste. The density of CRM decreases with the increase in CR percentage, as the inclusion of $C R$ causes the air content to increase. Due to the non-polar nature of $C R$ particles, they are able to entrap air and repel water on its surface, leading to higher porosity and water absorption of CRM. Herrero et al. [18] have investigated the properties of CRM by partially replacing sand with CR at $30 \%$ to $60 \%$ by weight. Their findings have shown that the toughness, acoustic insulation, and thermal insulation increase as the percentage of $C R$ increases. This is attributed to the elastic and energy dissipating characteristics of $\mathrm{CR}$ as a vibration-absorbing material.

Nanoparticles are used in concrete to enhance its performance and sustainability, such as compressive strength [19], flexural strength [20], tensile strength [21], ME [22], Poisson's Ratio (PR) [23], electrical resistivity [24], cohesiveness [25], hydration rate [26], impermeability [21], and durability [27]. Nano-silica (NS) in concrete has two levels of effects which are the chemical effect and physical effect. In terms of chemical effect, through pozzolanic reaction, more calcium silicate hydrate (C-S-H) gel at final stages is formed as NS reacts with calcium hydroxide $\left(\mathrm{Ca}(\mathrm{OH})_{2}\right)$, hence giving more strength, impermeability, and durability characteristics to the concrete [19]. While on the physical effect, it is able to decrease and densify the interfacial transition zone (ITZ) between the hardened cement matrix and aggregates due to its nano size. This leads to a lower porosity concrete with high performance [19]. In addition, when the nanoparticles are uniformly dispersed into the cement paste, they will act as a nucleus to tightly bond with cement hydrate and eventually enhance the hydration due to their large area-to-volume ratio [28]. Therefore, the objectives of this research work are to determine experimentally the mechanical properties of crumb rubber mortar containing nano-silica (NS-CRM) and to develop statistical models to predict these properties using Response Surface Methodology (RSM).

\section{Materials and Methods}

\subsection{Materials Compositions and Properties}

In this study, the cementitious materials used were ordinary Portland cement (OPC) and nano-silica (NS). Fine aggregates used were river sand and crumb rubber (CR). Included in the mixture were ordinary tap water and superplasticizer (SP). Type I Portland cement was used in the preparation of mortar mixes, and it meets the requirements of American Society for Testing Materials (ASTM) C150 [29]. NS used was in the form of white powder with electron grade standard, average particle sizes of $10 \mathrm{~nm}$ to $25 \mathrm{~nm}$ and density of $0.15 \mathrm{~g} / \mathrm{cm}^{3}$. The NS was used to partially replace $0 \%, 2.5 \%$, and $5 \%$ of cement by weight. Substituting a high percentage of NS will cause a further reduction in strengths, and it is uneconomical [30]. The chemical compositions and the physical properties of cement and NS are presented in Tables 1 and 2 below. River sand with particle sizes of $0.3 \mathrm{~mm}$ to $1.18 \mathrm{~mm}$ was used and it meets the requirements of ASTM C144-18 [31]. CR with particle sizes of $0.3 \mathrm{~mm}$ to $2.36 \mathrm{~mm}$ was used to partially replace $0 \%, 7.5 \%$, and $15 \%$ of river sand by volume. It was determined from the available literature that using a high percentage of $C R$ replacement will lead to a dramatic reduction in the strengths of 
CRM $[17,32]$. Table 3 shows the physical properties of river sand and CR used. Figure 1 illustrates the particle size distribution (PSD) graph of fine aggregates used. Ordinary tap water available in the laboratory was used and the quality conforms to the requirement of ASTM C1602/C1602M-18 [33]. Aqueous solution of modified polycarboxylates under the brand name of Sika Viscocrete-2044 was used in the mortar mixes. Table 4 shows the chemical compositions of SP used.

Table 1. Chemical compositions of cementitious materials.

\begin{tabular}{ccc}
\hline Chemical Compositions & Cement (\%) & Nano-Silica (\%) \\
\hline $\mathrm{CaO}$ & 62.85 & - \\
$\mathrm{SiO}_{2}$ & 25.21 & 99.80 \\
$\mathrm{Al}_{2} \mathrm{O}_{3}$ & 4.59 & - \\
$\mathrm{Fe}_{2} \mathrm{O}_{3}$ & 2.99 & - \\
$\mathrm{MgO}$ & 1.70 & - \\
$\mathrm{Na} 2$ & 0.98 & - \\
$\mathrm{K}_{2} \mathrm{O}$ & 1.68 & - \\
Loss of Ignition & 2.02 & 6.00 \\
\hline
\end{tabular}

Table 2. Physical properties of cementitious materials.

\begin{tabular}{ccc}
\hline Physical Properties & Cement & Nano-Silica \\
\hline Specific Gravity $\left(\mathrm{kg} / \mathrm{cm}^{3}\right)$ & 3.15 & - \\
Density $\left(\mathrm{g} / \mathrm{cm}^{3}\right)$ & 3.02 & 0.15 \\
Average Particle Size $(\mathrm{nm})$ & 13 & $10-25$ \\
Specific Surface Area $\left(\mathrm{cm}^{2} / \mathrm{g}\right)$ & 0.38 & $100 \pm 25$ \\
\hline
\end{tabular}

Table 3. Physical properties of fine aggregates.

\begin{tabular}{ccc}
\hline Physical Properties & Sand & Crumb Rubber \\
\hline Specific Gravity $\left(\mathrm{kg} / \mathrm{cm}^{3}\right)$ & 2.65 & 0.95 \\
Fineness Modulus & 2.20 & 0.92 \\
Water Absorption $(\%)$ & 2.10 & - \\
Moisture Content $(\%)$ & 1.30 & - \\
\hline
\end{tabular}

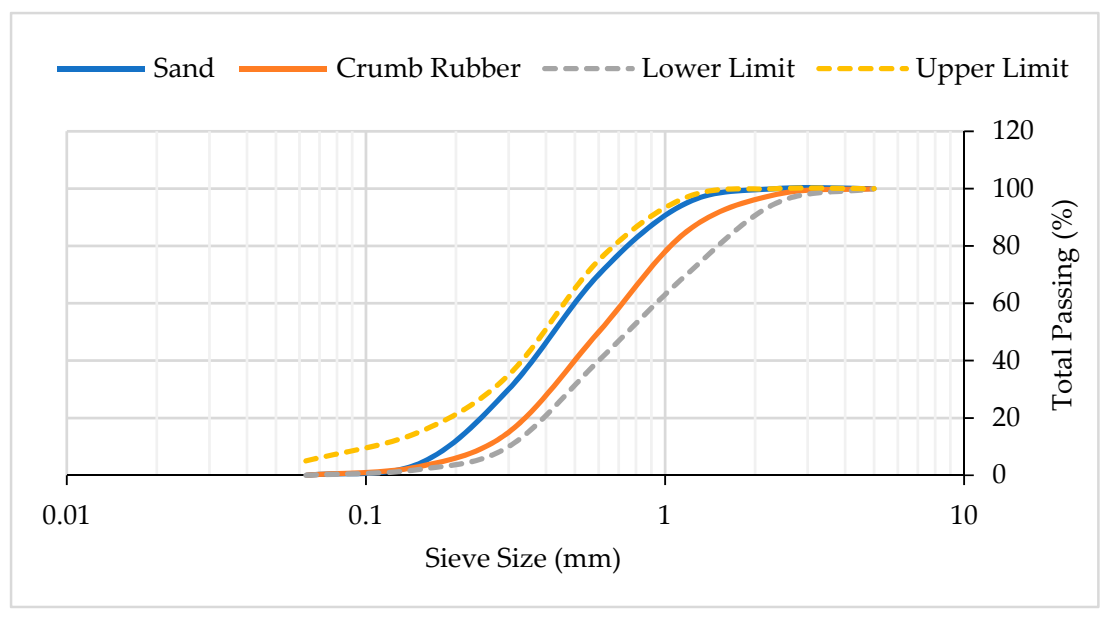

Figure 1. Particle size distribution graph of fine aggregates. 
Table 4. Chemical compositions of superplasticizer.

\begin{tabular}{cc}
\hline Chemical Composition & Aqueous solution of modified polycarboxylates \\
Appearance/Color & Brownish liquid, clear to slightly cloudy \\
pH-value & $3-5$ \\
Total Chloride Ion Content (\%) & $<0.1$ \\
\hline
\end{tabular}

\subsection{Mix Proportions}

For all mixes, the water to cementitious materials $(\mathrm{w} / \mathrm{c})$ ratio and sand to cementitious materials $(\mathrm{s} / \mathrm{c})$ ratio were kept constant at 0.35 and 1.5 , respectively. In order to study the mechanical properties of NS-CRM, thirteen mixes were prepared using Response Surface Methodology (RSM) with different ratios of NS $(0 \%, 2.5 \%, 5 \%)$ as partial replacement to cement by weight, while CR was replaced at varying percentages $(0 \%, 7.5 \%, 15 \%)$ by volume of river sand. Each mixture was given a distinctive name as shown in Table 5. For instance, mixture CR7.5-NS2.5 was a mortar mixture with $7.5 \%$ CR and $2.5 \%$ NS. There were five mix designs which contained the same percentage of CR and NS. These repetitive designs produced by RSM were to ensure they measured the pure error and stabilized the variance of the predicted responses.

Table 5. Constituent materials for mortar mixes.

\begin{tabular}{|c|c|c|c|c|c|c|c|}
\hline No & Mix & $\begin{array}{l}\text { Cement } \\
\left(\mathrm{kg} / \mathrm{m}^{3}\right)\end{array}$ & $\begin{array}{c}\text { Sand } \\
\left(\mathrm{kg} / \mathrm{m}^{3}\right)\end{array}$ & $\begin{array}{c}\text { Water } \\
\left(\mathrm{kg} / \mathrm{m}^{3}\right)\end{array}$ & $\begin{array}{c}\text { NS } \\
\left(\mathrm{kg} / \mathrm{m}^{3}\right)\end{array}$ & $\begin{array}{c}\text { CR } \\
\left(\mathrm{kg} / \mathrm{m}^{3}\right)\end{array}$ & $\begin{array}{c}\mathrm{SP} \\
\left(\mathrm{kg} / \mathrm{m}^{3}\right)\end{array}$ \\
\hline 1 & CR0-NSO & 0.1126 & 0.1688 & 0.0394 & 0.0000 & 0.0000 & 0.0198 \\
\hline 2 & CR7.5-NS0 & 0.1126 & 0.1560 & 0.0394 & 0.0000 & 0.0126 & 0.0228 \\
\hline 3 & CR15-NS0 & 0.1126 & 0.1434 & 0.0394 & 0.0000 & 0.0254 & 0.0361 \\
\hline 4 & CR0-NS2.5 & 0.1096 & 0.1688 & 0.0394 & 0.0028 & 0.0000 & 0.0217 \\
\hline 5 & CR7.5-NS2.5 & 0.1096 & 0.1560 & 0.0394 & 0.0028 & 0.0126 & 0.0257 \\
\hline 6 & CR7.5-NS2.5 & 0.1096 & 0.1560 & 0.0394 & 0.0028 & 0.0126 & 0.0255 \\
\hline 7 & CR7.5-NS2.5 & 0.1096 & 0.1560 & 0.0394 & 0.0028 & 0.0126 & 0.0260 \\
\hline 8 & CR7.5-NS2.5 & 0.1096 & 0.1560 & 0.0394 & 0.0028 & 0.0126 & 0.0250 \\
\hline 9 & CR7.5-NS2.5 & 0.1096 & 0.1560 & 0.0394 & 0.0028 & 0.0126 & 0.0263 \\
\hline 10 & CR15-NS2.5 & 0.1096 & 0.1434 & 0.0394 & 0.0028 & 0.0254 & 0.0381 \\
\hline 11 & CR0-NS5 & 0.1068 & 0.1688 & 0.0394 & 0.0056 & 0.0000 & 0.0228 \\
\hline 12 & CR7.5-NS5 & 0.1068 & 0.1560 & 0.0394 & 0.0056 & 0.0126 & 0.0283 \\
\hline 13 & CR15-NS5 & 0.1068 & 0.1434 & 0.0394 & 0.0056 & 0.0254 & 0.0400 \\
\hline
\end{tabular}

where NS: Nano-silica, CR: Crumb rubber, SP: Superplasticizer.

\subsection{Response Surface Methodology}

Response Surface Methodology (RSM) discovers the relationships between one or more response variables [34]. RSM uses a series of designed experiments to achieve an ideal response. It is a specialized statistical method which is most commonly used for simulating processes and experiments [35]. RSM is implemented using Design-Expert 10 software where runs are known as a trial of progression tests and the output response depends solely on the input data variables. For this study, Central Composite Design (CCD) was chosen as the design tool. CCD is an effective design choice that is suitable for sequential experimentation [36]. It allows a reasonable amount of information for testing the lack of fit where it does not involve an unusually large number of design points [37].

In this study, two variables were used as partial substitutes, which were CR and NS. Sand was replaced by CR in varying volumes of $0 \%, 7.5 \%$ and $15 \%$. Cement was replaced by NS in varying weight of $0 \%, 7.5 \%$, and $15 \%$. Thirteen mixes were established by the RSM software, using various combinations of the variables as illustrated in Table 5. For each mix, the amount of water used was kept constant. The 28 days compressive strength, flexural tensile strength, direct tensile strength, drying shrinkage, Modulus of Elasticity (ME), and Poisson's Ratio (PR) of each of the mixes was determined in the laboratory and was considered as the responses for the RSM analysis and mixtures optimization. 


\subsection{Sample Preparations and Test Methods}

Thirteen design mixes of mortar were recommended by the CCD tool and each design mix contained three specimens with three replicates that were cast, cured, and tested. The first step involved the preparation of materials and specimens. At this stage, preparation of molds, mixing of NS with ordinary tap water, mixing of SP with ordinary tap water, and sieving of fine aggregates were performed. Next, cement, river sand, and CR were dry mixed for about 3 to $5 \mathrm{~min}$. Then NS, water, and SP were added, and the mixing continued for about 5 to $7 \mathrm{~min}$. Finally, the specimens were cast and demolded after $24 \mathrm{~h}$. They were kept in the laboratory curing tank with a temperature of $20^{\circ} \mathrm{C} \pm 2{ }^{\circ} \mathrm{C}$ until they were ready to be tested. To observe changes in strengths of each mix, testing of specimens took place on day 7,14 , and 28 .

After all specimens were tested, the results were then input into the CCD. Each response was then analyzed to produce the Analysis of Variance (ANOVA), diagnostics, and model graphs. Next, numerical optimization was done by setting the goals for each response. Once the goals were set up, the software generated a few optimal conditions (optimized mix proportions) for each response that need to be verified by conducting laboratory work. These new optimized mix proportions were then cast, cured, and tested. The results for each test were recorded. Lastly, the percentage error between the experimental and theoretical strengths was calculated. Table 6 shows the details of specimens used, size of molds, test conditions, and the ASTM standards for the different types of tests.

Table 6. Test methods for mortar mixes.

\begin{tabular}{|c|c|c|c|c|c|}
\hline Tests & Specimens & $\begin{array}{l}\text { Size of Molds } \\
(\mathrm{mm})\end{array}$ & Test Machines & Test Conditions & Standards \\
\hline Sieve Analysis & - & - & $\begin{array}{l}\text { Sieve Shaker } \\
\text { Machines }\end{array}$ & $\begin{array}{l}\text { Operate machine } \\
\text { for } 15 \text { to } 20 \mathrm{~min}\end{array}$ & $\begin{array}{c}\text { ASTM } \\
\text { C136/C136M-14 } \\
{[38]}\end{array}$ \\
\hline Flow Table & - & - & $\begin{array}{l}\text { Flow Table with } \\
\text { Mold and Tamping } \\
\text { Rod }\end{array}$ & $\begin{array}{c}\text { Acceptable flow of } \\
110 \pm 5 \% \text { with } \\
25 \text { drops in } 15 \mathrm{~s}\end{array}$ & $\begin{array}{c}\text { ASTM C1437-13 } \\
\text { [39] }\end{array}$ \\
\hline $\begin{array}{l}\text { Compressive } \\
\text { Strength }\end{array}$ & Cube & $50 \times 50 \times 50$ & $\begin{array}{l}\text { ELE ADR } 3000 \\
\text { Machine }\end{array}$ & $\begin{array}{l}\text { Continuous load } \\
\text { rate of } 0.9 \mathrm{kN} / \mathrm{s}\end{array}$ & $\begin{array}{c}\text { ASTM } \\
\text { C109/C109M-16a } \\
{[40]}\end{array}$ \\
\hline $\begin{array}{l}\text { Flexural Tensile } \\
\text { Strength }\end{array}$ & Prism & $25 \times 100 \times 500$ & $\begin{array}{l}200 \text { kN Universal } \\
\text { Testing Machine }\end{array}$ & $\begin{array}{l}\text { Continuous speed } \\
\text { rate of } 5 \mathrm{~mm} / \mathrm{min}\end{array}$ & ASTM C348-18 [41] \\
\hline $\begin{array}{l}\text { Direct Tensile } \\
\text { Strength }\end{array}$ & Dog-bone & $50 \times 200 \times 25$ & $\begin{array}{l}200 \text { kN Universal } \\
\text { Testing Machine }\end{array}$ & $\begin{array}{c}\text { Gradual speed rate } \\
\text { of } 0.15 \mathrm{~mm} / \mathrm{s}\end{array}$ & $\begin{array}{c}\text { ASTM D2936-20 } \\
\text { [42] }\end{array}$ \\
\hline Drying Shrinkage & Two-gang Prism & $285 \times 25 \times 30$ & $\begin{array}{l}\text { Digital Vernier } \\
\text { Caliper }\end{array}$ & $\begin{array}{l}\text { Store in room with } \\
\text { temperature of } 20 \\
\pm 2{ }^{\circ} \mathrm{C}\end{array}$ & ASTM C596-18 [43] \\
\hline $\begin{array}{c}\text { Poisson's Ratio } \\
\text { Modulus of } \\
\text { Elasticity }\end{array}$ & Cylinder & $150 \times 300$ & $\begin{array}{c}\text { Digital Dial Gauge } \\
\text { Compressometer- } \\
\text { Extensometer and } \\
\text { ELE ADR } 3000 \\
\text { Machine }\end{array}$ & $\begin{array}{l}\text { Continuous load } \\
\text { rate of } 5.3 \mathrm{kN} / \mathrm{s}\end{array}$ & $\begin{array}{c}\text { ASTM } \\
\text { C469/C469M-14 } \\
{[44]}\end{array}$ \\
\hline SEM & Crushed sample & - & $\begin{array}{c}\text { Pascal } 440 \text { EVO } \\
\text { Machine }\end{array}$ & $\begin{array}{l}\text { Crushed sample } \\
\text { size of } 1 \times 1 \mathrm{~cm}\end{array}$ & $\begin{array}{c}\text { ASTM C1723-16 } \\
{[45]}\end{array}$ \\
\hline MIP & Crushed sample & - & EVO LS15 Machine & $\begin{array}{l}\text { Crushed sample } \\
\text { size of } 1 \times 1 \mathrm{~cm}\end{array}$ & $\begin{array}{c}\text { ASTM D4404-18 } \\
\text { [46] }\end{array}$ \\
\hline
\end{tabular}




\section{Results and Discussion}

\subsection{Effect of Crumb Rubber and Nano-Silica on Hardened Properties of NS-CRM \\ 3.1.1. Compressive Strength}

The compressive strength results of crumb rubber mortar containing nano-silica (NSCRM) are presented in Figure 2. A considerable decrease in the compressive strengths was observed with an increasing percentage use of crumb rubber (CR). The strengths decreased by $50.3 \%$ and $68.7 \%$ when incorporating $7.5 \%$ and $15 \%$ of CR at $0 \%$ of NS. This trend is expected due to the hydrophobic nature of $\mathrm{CR}$ which repulses water and traps air on its surface, leading to weak bonding between the cement matrix and CR particles. The poor bonding leads to the thickening of the interfacial transition zone (ITZ) and the lowering of stress transfer. Furthermore, the trapped air on the CR surface becomes void and increases the porosity of the hardened mortar, consequently leading to a lower strength.

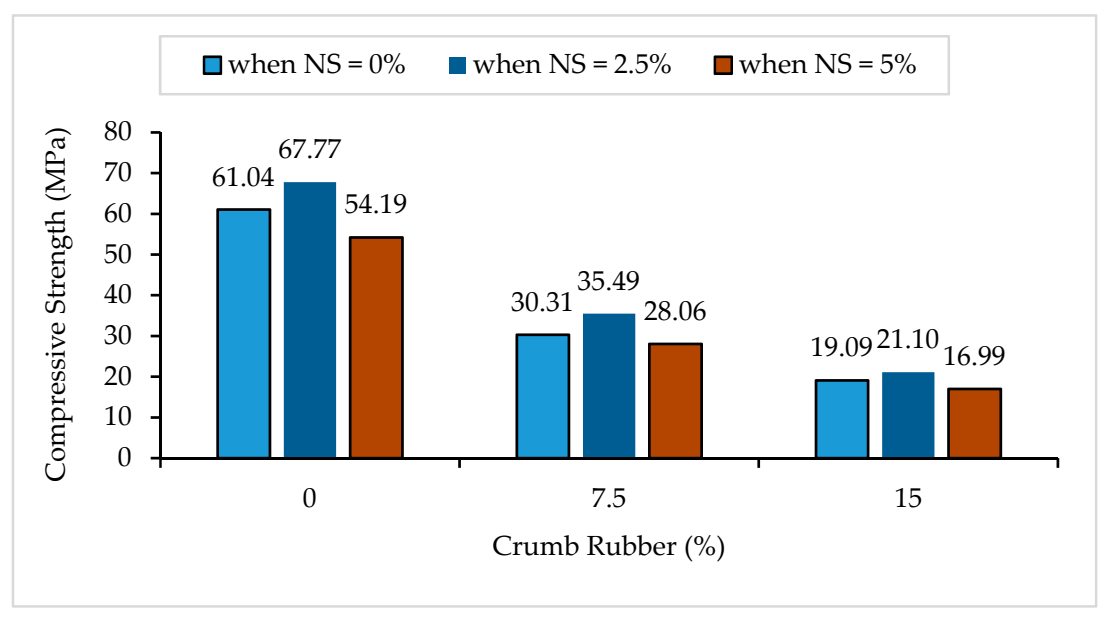

Figure 2. Compressive strength of NS-CRM mixes at 28 days.

It was observed that the increase in NS from $0 \%$ to $2.5 \%$ had a good influence on the compressive strengths of mortar. The strengths increased by $11.0 \%, 17.1 \%$, and $10.5 \%$ between samples having $0 \%$ and $2.5 \%$ of NS content at $0 \%, 7.5 \%$, and $15 \%$ of CR replacement, respectively. The positive effect of NS on the compressive strengths is attributed to its physico-chemical effect within the mortar. In a secondary hydration reaction, the NS reacts with calcium hydroxide $\left(\mathrm{Ca}(\mathrm{OH})_{2}\right)$ liberated from cement hydration to form more calcium silicate hydrate (C-S-H) gel [47]. This is known as a pozzolanic reaction. The $\mathrm{C}-\mathrm{S}-\mathrm{H}$ produced from the cement hydration and the pozzolanic reaction is responsible for the strength of the mortar [27]. On the physical effect, the nano-sized particles of the NS fill up the voids within the matrix, thereby densifying and refining the pore structure of the mortar $[28,48]$. However, at a higher NS percentage of $5 \%$, a sudden drop in compressive strengths were observed for all CR replacements. This is due to the excessive content of NS which acts as a nano-aggregate within the CRM and leads to a less dense microstructure [20].

The failure mode of the NS-CRM is influenced by the CR and NS content. At $0 \%$ $\mathrm{CR}$ and NS, the NS-CRM experienced brittle failure mode as shown Figure 3a-c. The severity of the failure increased at higher NS percentages. This is due to the increase in toughness of the mortar by the NS. However, as the CR replacement increased, the failure mode became less severe as illustrated in Figure $3 \mathrm{~d}-\mathrm{i}$ for $7.5 \%$ and $15 \%$ of CR replacements, respectively. This is attributed to the enhanced energy absorption capacity of the NS-CRM with increasing CR percentage. As reported by Yilmaz and Degirmenci [49], the addition of CR particles having low stiffness increase the flexibility of the CRM, allowing it to absorb more energy and exhibit a lower number of cracks at failure despite having low strength. 


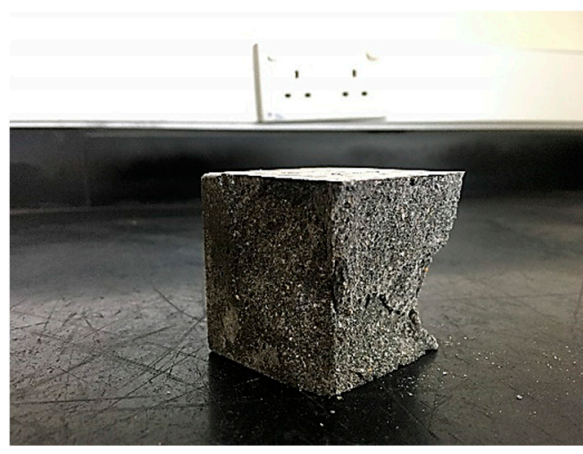

(a)

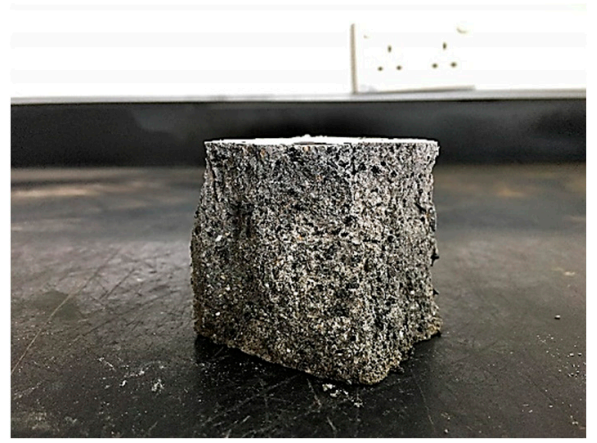

(d)

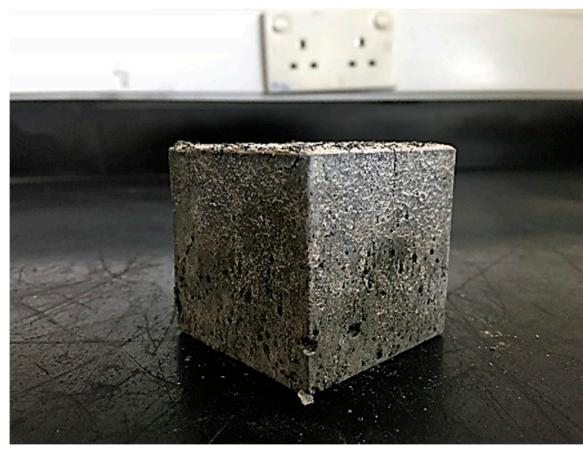

(g)

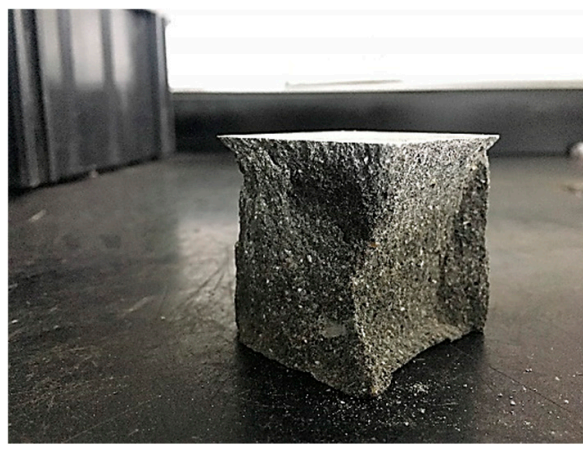

(b)

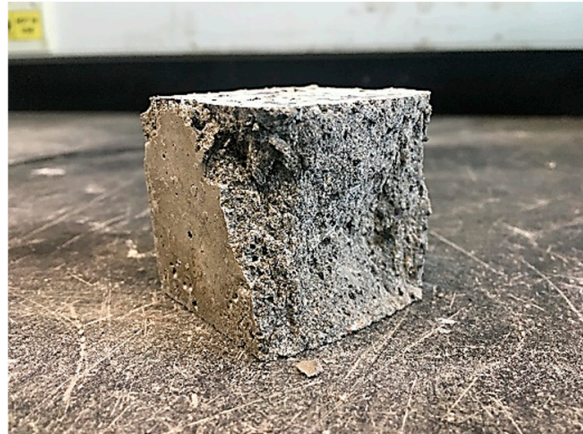

(e)

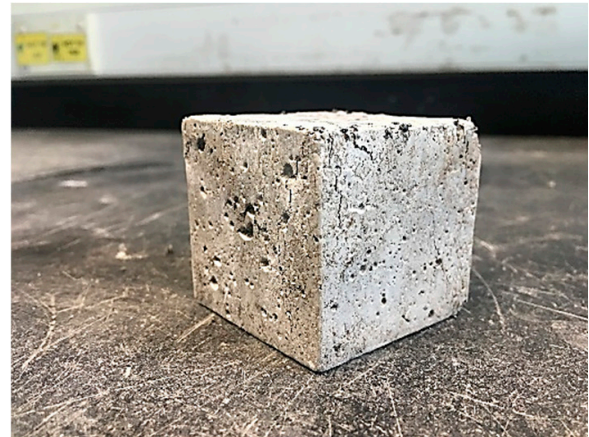

(h)

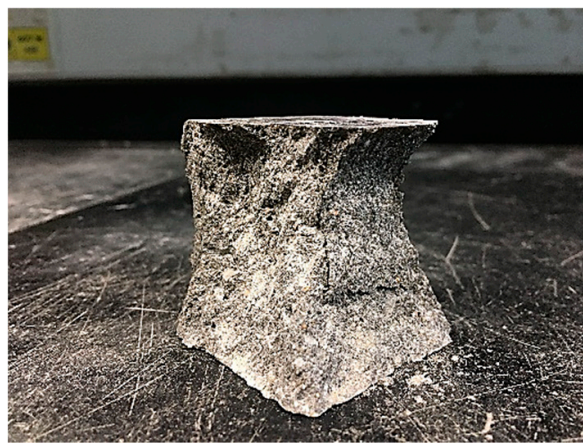

(c)

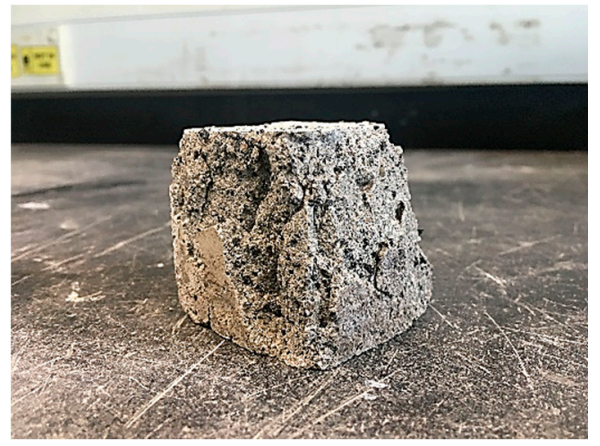

(f)

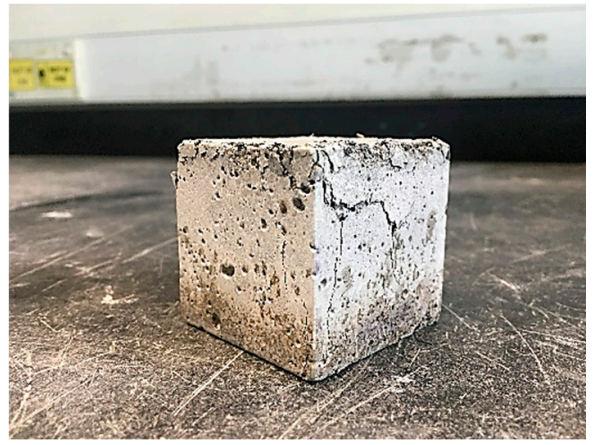

(i)

Figure 3. Crushed cube samples of NS-CRM mixes at 28 days: (a) CR0-NS0; (b) CR0-NS2.5; (c) CR0-NS5; (d) CR7.5-NS0; (e) CR7.5-NS2.5; (f) CR7.5-NS5; (g) CR15-NS0; (h) CR15-NS2.5; (i) CR15-NS5.

\subsubsection{Flexural Tensile Strength}

The flexural tensile strength results of NS-CRM are illustrated in Figure 4 . An enormous decrease in the flexural tensile strengths was observed with an increasing percentage use of CR. The strengths decreased by $31.9 \%$ and $60.9 \%$ when incorporating $7.5 \%$ and $15 \%$ $\mathrm{CR}$ at $0 \%$ NS. The declining trend in the strengths of mortar samples is primarily due to the hydrophobic characteristic of CR that leads to a higher void content in the mortar. It allows stress concentration across the pore to happen, thus causing formation of micro-cracks [50]. Besides, CR is not compatible with sand. It has lower strength, stiffness, specific gravity, and load-carrying capacity, leading to a reduction in strength when replaced with a portion of sand [49]. Moreover, the presence of CR leads to a more porous hardened mortar due to the change of aggregate grading in the mortar mix from continuous to a non-continuous grading. Hence, it causes more cavities to form due to the inability of the voids in the aggregate to be filled by the CR particles [51]. As the percentage of CR was increased, the mortar samples behavior substantially changed from brittle to ductile when the peak strength was reached. This is due to the elastic properties [52] and better energy absorption [4] of CR. 
Figure 5 shows that the mortar samples containing higher percentage of $C R$ were able to withstand the load for a longer period of time before they broke into two, regardless of them having low flexural tensile strength.

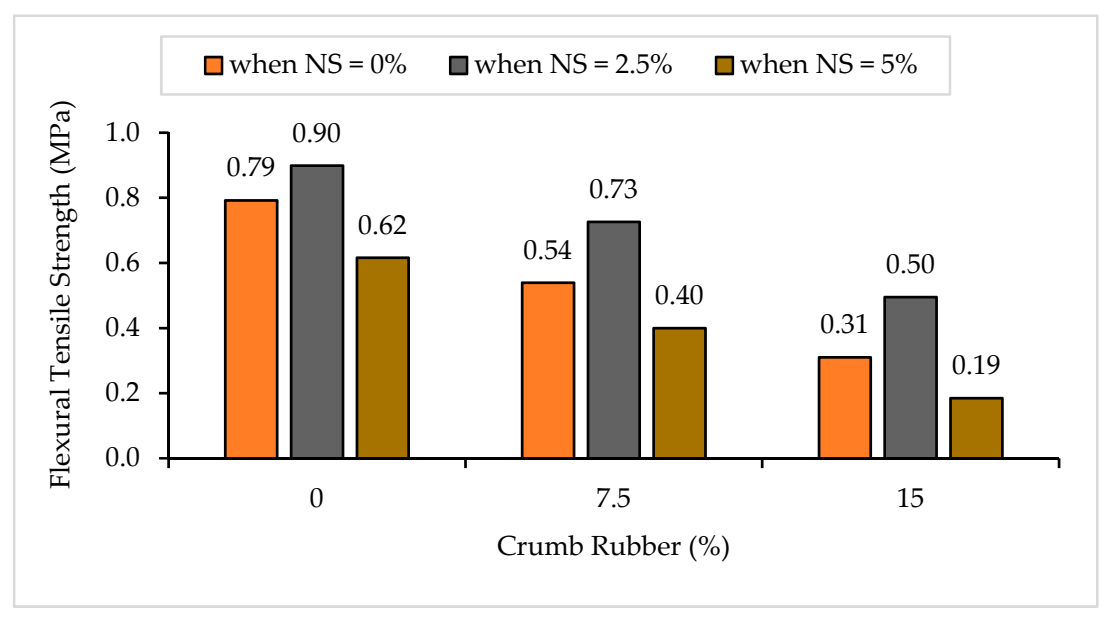

Figure 4. Flexural tensile strength of NS-CRM mixes at 28 days.

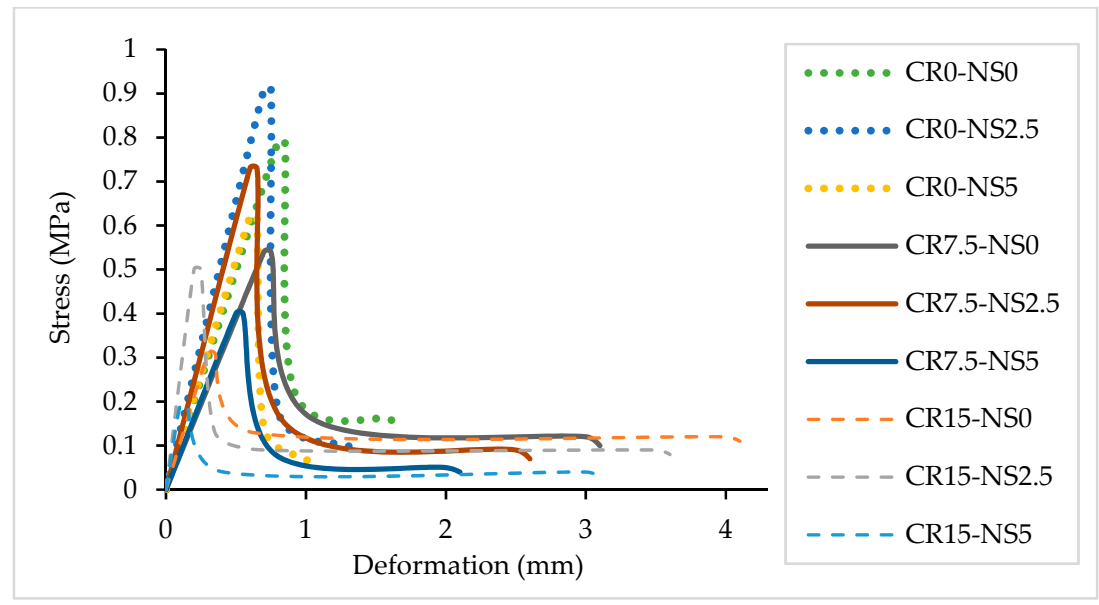

Figure 5. Deformation of NS-CRM samples at 28 days.

In contrast, it was observed that the increase in NS from $0 \%$ to $2.5 \%$ had a beneficial impact on the flexural tensile strengths. The strengths increased by $13.5 \%, 34.7 \%$, and $59.7 \%$ between samples having $0 \%$ and $2.5 \%$ of NS content at $0 \%, 7.5 \%$, and $15 \%$ of CR replacement, respectively. The positive effect of NS on the flexural tensile strengths is attributed to the physical properties of NS which acts as a filler in filling the nano-voids between aggregates and cement matrix [53]. Supported by Li et al. [28], NS has the capability to improve the strength, toughness, and stiffness of mortar due to its large area-to-volume ratio, therefore it acts as a physical filler in filling the nano-voids between cement and aggregates. However, when $5 \%$ of NS was incorporated into the mixture, an enormous drop in flexural tensile strength was observed for all CR replacements. This is due to the high percentage of NS which promotes the packing of particles, decreasing the volume between them and decreasing the free water in the mixture, hence causing a higher internal friction between solid particles [54].

\subsubsection{Direct Tensile Strength}

The direct tensile strength results of NS-CRM are presented in Figure 6. A general decline in the direct tensile strengths was observed with increasing percentage use of CR. The strengths decreased by $35.3 \%$ and $42.6 \%$ when incorporating $7.5 \%$ and $15 \%$ of CR at 
$0 \%$ of NS. The declining trend in the strengths of mortar samples is caused by the presence of air content in the mixture, due to the non-polar nature of CR particle which has the tendency to entrap air on its rough surface. Therefore, it may attract air because it has the propensity to repel water. It was observed that the crack failure occurred at a point of abrupt change in the cross-sectional area due to the high-stress level, as illustrated in Figure 7. Although the samples with $15 \%$ of $C R$ achieved low direct tensile strength, they remained intact even after failure. This indicates that the post-crack strength of the samples improves with the presence of CR particles. Supported by Yilmaz and Degirmenci [49], the control mortar samples split into two pieces immediately after cracking, whereas samples containing $\mathrm{CR}$ particles showed a larger deformation without complete disintegration.

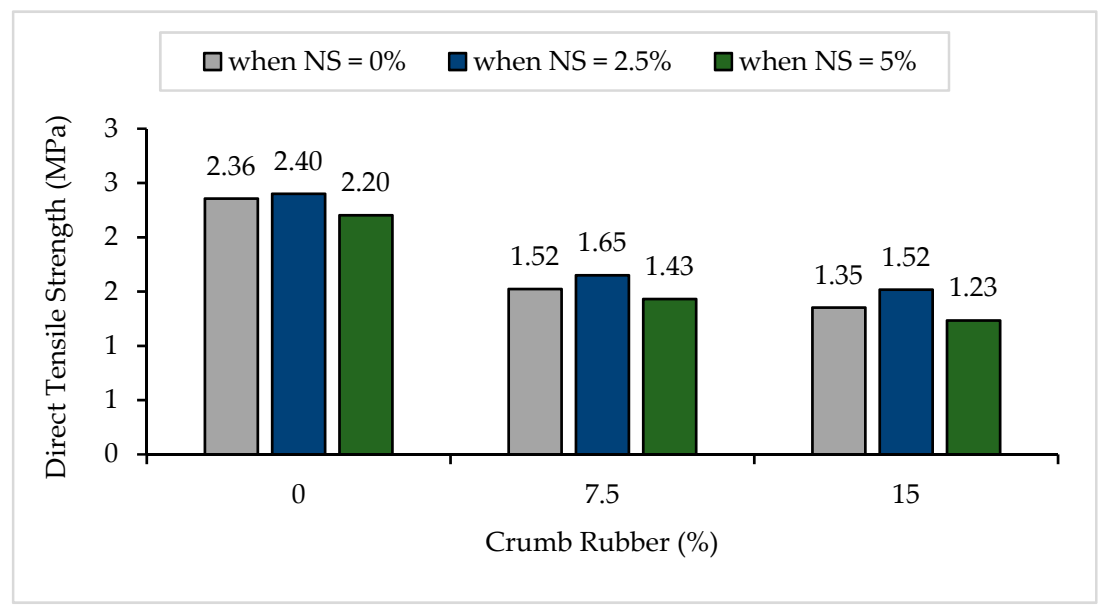

Figure 6. Direct tensile strength of NS-CRM mixes at 28 days.

Conversely, it was observed that the increase in NS from $0 \%$ to $2.5 \%$ had a positive influence on the direct tensile strength. The strengths increased by $1.9 \%, 8.3 \%$, and $12.1 \%$ between samples having $0 \%$ and $2.5 \%$ of NS content at $0 \%, 7.5 \%$, and $15 \%$ of CR replacement, respectively. NS enhances the durability, as well as the strength of the mortar mixture because the ultra-fine particles fill the voids of C-S-H structure and provide a more homogenous distribution of hydrated products. Furthermore, NS increases the density [55], reduces porosity, and improves the bond between aggregates and cement matrix [48]. However, it was observed that incorporating $5 \%$ of NS into the mixture had caused a slight drop in direct tensile strength for all CR replacements. According to Sobolev et al. [56], a higher percentage of NS replacing cement in the mixture does not lead to an improvement in the strength because of the improper dispersion of NS particles. Due to their high surface energy, the tendency towards agglomeration is high, thus leading to a weak zone created between the cement matrix and aggregates in the mortar. Therefore, it is vital to attain the composite materials with improved properties. 


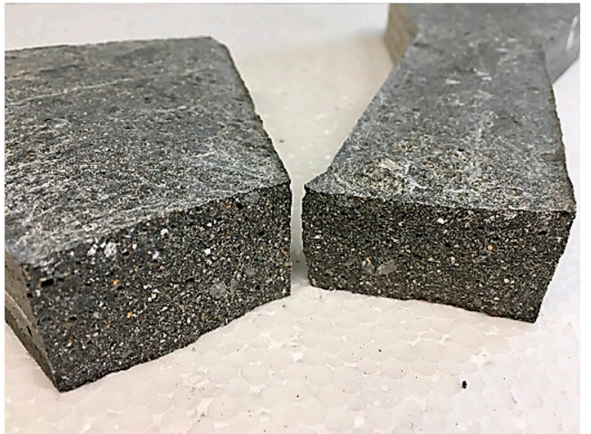

(a)

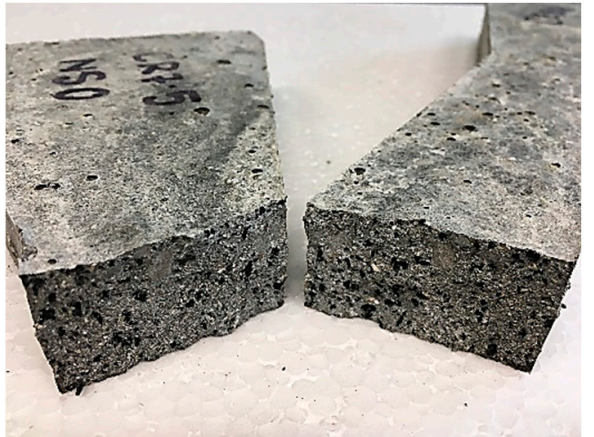

(d)

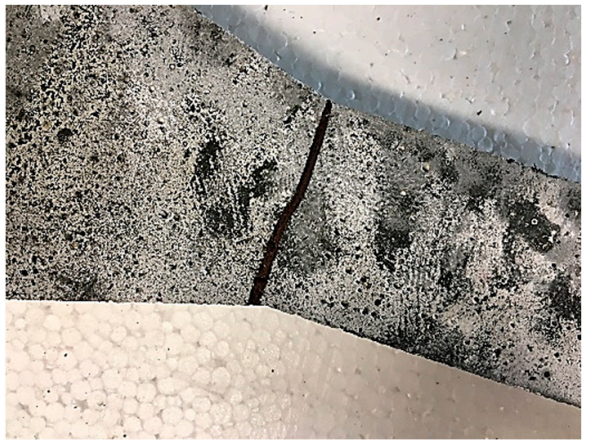

(g)

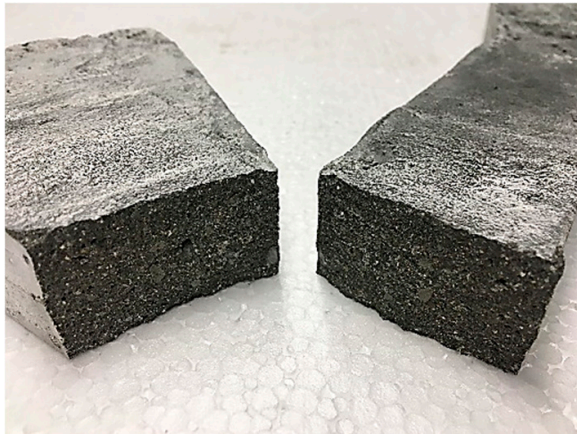

(b)

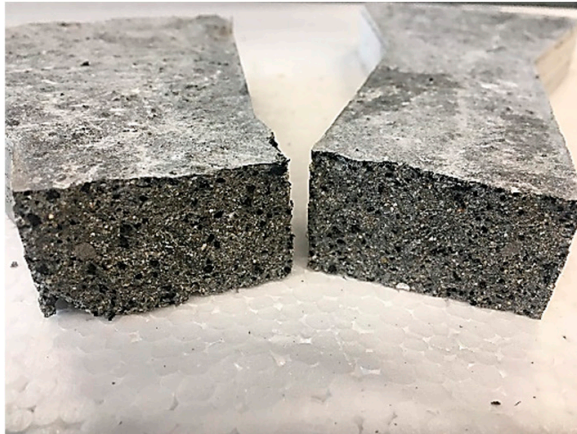

(e)

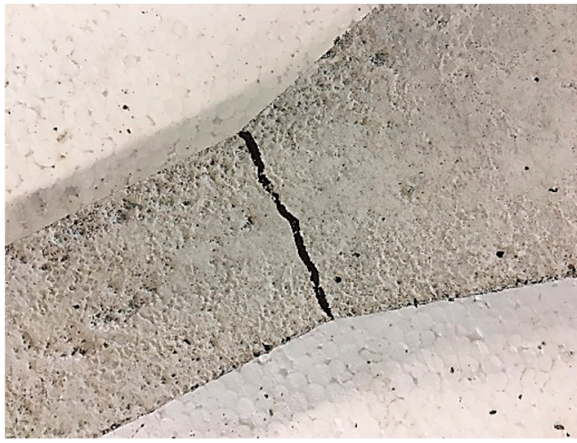

(h)

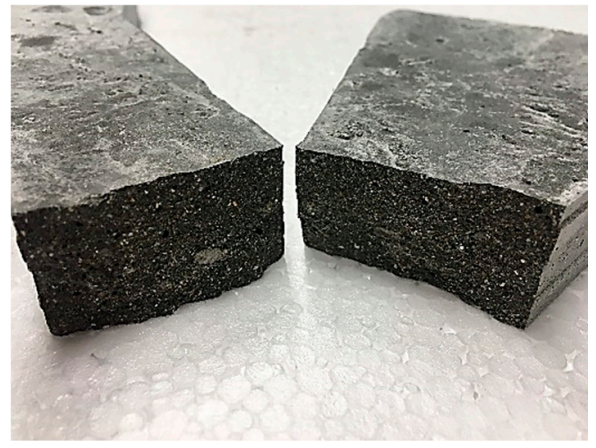

(c)

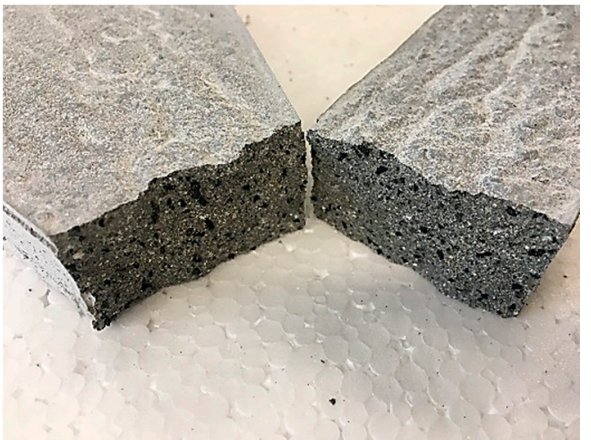

(f)

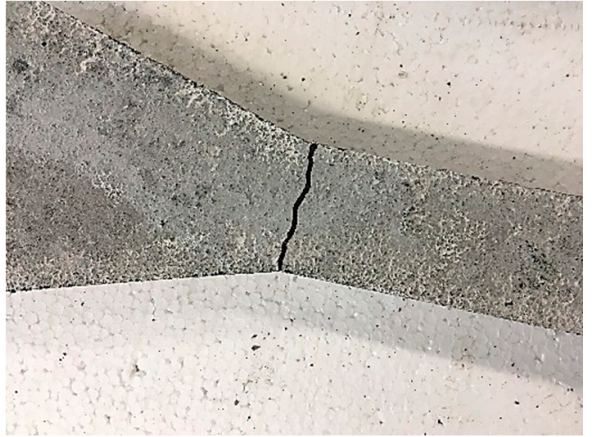

(i)

Figure 7. Tested dog-bone samples of NS-CRM mixes at 28 days: (a) CR0-NS0; (b) CR0-NS2.5; (c) CR0-NS5; (d) CR7.5-NS0; (e) CR7.5-NS2.5; (f) CR7.5-NS5; (g) CR15-NS0; (h) CR15-NS2.5; (i) CR15-NS5.

\subsubsection{Drying Shrinkage}

The drying shrinkage results of NS-CRM are illustrated in Figure 8. A steady incline in the shrinkage results was observed with an increasing percentage use of CR. The shrinkage results increased by $14.3 \%$ and $28.6 \%$ when incorporating $7.5 \%$ and $15 \%$ of CR at $0 \%$ of NS. According to Yu and Zhu [16], the CRM appears to depend on the size and content of CR. Clearly, as the CR percentage used is high, the drying shrinkage will be high too. The inclining trend in the shrinkage of mortar samples is because the CR causes an increment of air content and voids in the mortar mixture. 


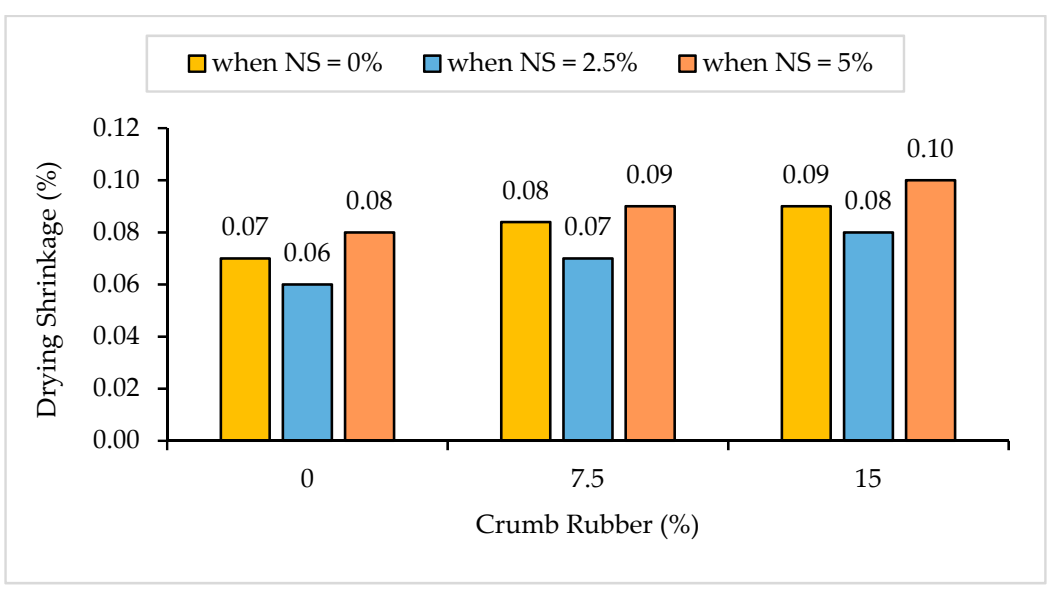

Figure 8. Drying shrinkage of NS-CRM mixes at 28 days.

On the contrary, it was observed that the increase in NS from $0 \%$ to $2.5 \%$ had a positive influence on the drying shrinkage results. The shrinkage results decreased by $14.3 \%, 12.5 \%$, and $11.1 \%$ between samples having $0 \%$ and $2.5 \%$ of NS content at $0 \%, 7.5 \%$, and $15 \%$ of CR replacement, respectively. Arzadnia et al. [57] have reported that the reduction in drying shrinkage of the hardened samples is due to the reduction in permeability of the mixture. The C-S-H produced from pozzolanic reaction of NS allows it to fill the capillary pores and restrain the loss of moisture in the pores, causing the drying shrinkage of the hardened samples to decrease. However, as the percentage of NS incorporated increased to $5 \%$, a substantial increase in NS-CRM drying shrinkage results were observed. Neto et al. [58] have stated that high replacement of cement by NS causes the alteration of pore size and increase in mesopores volume due to agglomeration of unreacted NS which leads to excessive self-desiccation.

\subsubsection{Modulus of Elasticity}

The Modulus of Elasticity (ME) results of NS-CRM are presented in Figure 9. A dramatic fall in the ME results was observed with increasing percentage use of $\mathrm{CR}$. The ME decreased by $45.4 \%$ and $68.4 \%$ when incorporating $7.5 \%$ and $15 \%$ of CR at $0 \%$ of NS. The sharp downward trend in the ME results is due to the physical properties of CR particles which are less stiff as compared to the hardened cement matrix in the mortar [49]. Therefore, it allows the CR to act as tiny springs inside the hardened mortar. In Figure 10, it was observed that the peak stress achieved by samples having $15 \%$ of CR content at $0 \%$, $2.5 \%$, and $5 \%$ of NS replacement were $15 \mathrm{MPa}, 18 \mathrm{MPa}$, and $19 \mathrm{MPa}$. Even so, the strain achieved was the highest due to the elastic properties of CR.

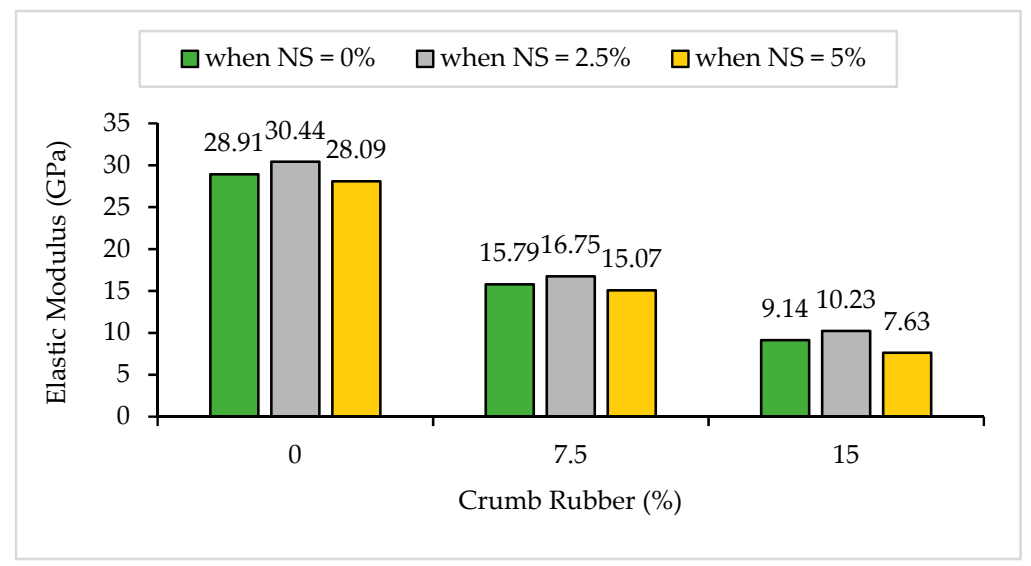

Figure 9. Modulus of Elasticity of NS-CRM mixes at 28 days. 


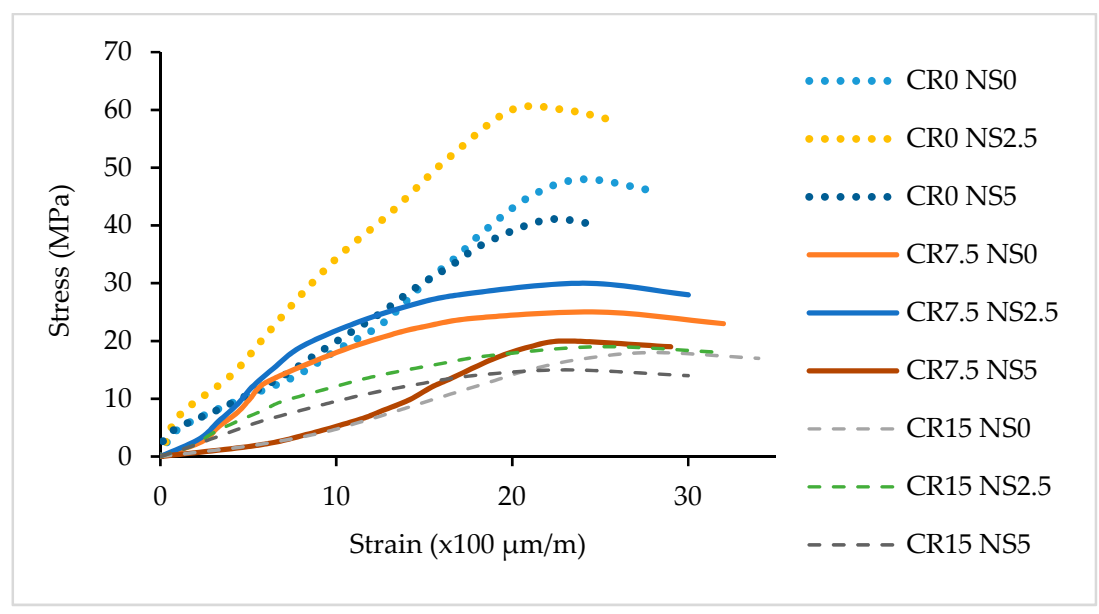

Figure 10. Stress-strain of NS-CRM mixes at 28 days.

However, it was observed that the increase in NS from $0 \%$ to $2.5 \%$ had a positive influence on the ME results. The ME increased by $5.3 \%, 6.1 \%$, and $11.9 \%$ between samples having $0 \%$ and $2.5 \%$ of NS content at $0 \%, 7.5 \%$, and $15 \%$ of CR replacement, respectively. According to Aleem et al. [30], the improvement of strength is due to the behavior of NS that acts as a filler to enhance the microstructure, as an activator to encourage pozzolanic reaction, along with acts as a nucleation effect with $\mathrm{Ca}(\mathrm{OH})_{2}$ to perform pozzolanic effects. Hence, it leads to more accumulation and precipitation of the hydrated products in the pores that are initially filled with water. Consequently, it leads to the formation of dense, compact, and homogeneous microstructure, and better stiffness of CRM. However, it was observed that incorporating $5 \%$ of NS into the mixture had caused a marginal drop in the ME for all CR replacements. Li et al. [59] have concluded that NS cannot be uniformly dispersed when a large quantity of it is used due to its great surface energy. Therefore, the unreacted NS causes agglomeration to occur and affects the microstructure of the CRM.

\subsubsection{Poisson's Ratio}

The Poisson's Ratio (PR) results of NS-CRM are illustrated in Figure 11. A gradual decline in the PR results was observed with increasing percentage use of CR. The PR decreased by $50.0 \%$ and $83.8 \%$ when incorporating $7.5 \%$ and $15 \%$ of CR at $0 \%$ of NS. The declining trend in the PR results is due to the presence of CR which is less stiff as compared to the hardened cement matrix in the mortar [49]. Due to the elastic properties of CR [52], it acts as a tiny spring in the hardened mortar which leads to an increase in the deformability of the CRM and consequently decreasing the PR. Sideris et al. [60] have implied that there is a linear relationship between $\mathrm{ME}, \mathrm{PR}$, and compressive strength of mortar. Sideris [61] added that the linear relationship between compressive strength of mortar leads to the possibility of estimating the ME and PR. Therefore, incorporating a high percentage of CR leads to lower compressive strength due to the non-polar nature of CR. Subsequently, decreases the ME due to the fact that there is a concentration of stress at the aggregate-mortar interface due to the large difference in the ME between the aggregate and the mortar [62] and hence, causing the PR to decrease as well. 


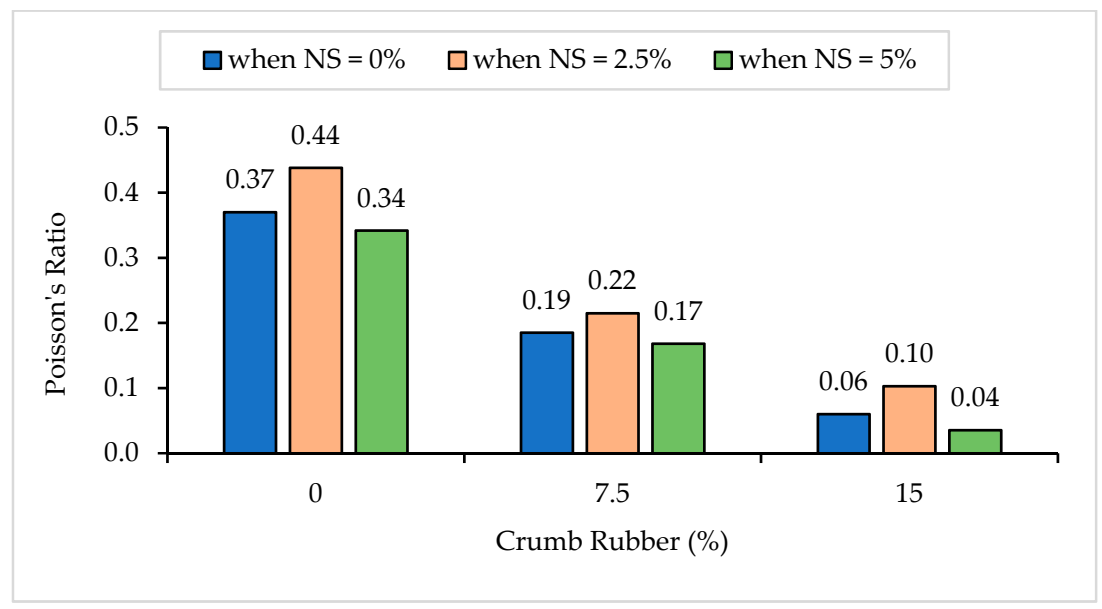

Figure 11. Poisson's Ratio of NS-CRM mixes at 28 days.

Nonetheless, it was observed that the increase in NS from $0 \%$ to $2.5 \%$ had a positive impact on the PR. The PR increased by $18.4 \%, 16.2 \%$, and $71.7 \%$ between samples having $0 \%$ and $2.5 \%$ of NS content at $0 \%, 7.5 \%$, and $15 \%$ of CR replacement, respectively. Mukharjee et al. [63] have stated that the physical effect is due to the nano-size of NS particles which are able to fill up the nano-sized voids of the ITZ. The chemical effect is due to the physico-chemical effect in which NS reacts with the $\mathrm{Ca}(\mathrm{OH})_{2}$ and generates more C-S-H gel. Thus, this leads to the densification of the ITZ and consequently decreases its thickness. However, it was observed that incorporating $5 \%$ of NS into the mixture had caused a marginal drop in the PR for all CR replacements. This happens due to the high percentage of NS incorporated, which leads to the agglomeration of unreacted NS.

\subsection{Mathematical and Statistical Models Using Response Surface Methodology}

\subsubsection{Response Surface Methodology Modeling}

The experimental mix designs and the results are presented in Table 7 below. For each mix design, three samples with three replicates were prepared. Thus, the results presented in the table below were the average of three samples tested.

Table 7. Experimental design matrix and responses for NS-CRM.

\begin{tabular}{|c|c|c|c|c|c|c|c|c|c|}
\hline No & Mix & CR (\%) & NS (\%) & $\sigma_{\mathrm{c}}(\mathrm{MPa})$ & $\sigma_{\mathrm{f}}(\mathrm{MPa})$ & $\sigma_{\mathrm{d}}(\mathrm{MPa})$ & Dry Shrinkage (\%) & ME (GPa) & PR \\
\hline 1 & CR0-NSO & 0 & 0 & 61.04 & 0.79 & 2.36 & 0.07 & 28.91 & 0.37 \\
\hline 2 & CR7.5-NS0 & 7.5 & 0 & 30.31 & 0.54 & 1.52 & 0.08 & 15.79 & 0.19 \\
\hline 3 & CR15-NS0 & 15 & 0 & 19.09 & 0.31 & 1.35 & 0.09 & 9.14 & 0.06 \\
\hline 4 & CR0-NS2.5 & 0 & 2.5 & 67.77 & 0.90 & 2.40 & 0.06 & 30.44 & 0.44 \\
\hline 5 & CR7.5-NS2.5 & 7.5 & 2.5 & 35.49 & 0.73 & 1.65 & 0.07 & 16.74 & 0.22 \\
\hline 6 & CR7.5-NS2.5 & 7.5 & 2.5 & 35.45 & 0.78 & 1.63 & 0.07 & 16.01 & 0.25 \\
\hline 7 & CR7.5-NS2.5 & 7.5 & 2.5 & 36.11 & 0.72 & 1.64 & 0.07 & 17.23 & 0.20 \\
\hline 8 & CR7.5-NS2.5 & 7.5 & 2.5 & 34.90 & 0.72 & 1.66 & 0.07 & 17.08 & 0.19 \\
\hline 9 & CR7.5-NS2.5 & 7.5 & 2.5 & 35.50 & 0.72 & 1.67 & 0.07 & 16.71 & 0.21 \\
\hline 10 & CR15-NS2.5 & 15 & 2.5 & 21.10 & 0.50 & 1.52 & 0.08 & 10.23 & 0.10 \\
\hline 11 & CR0-NS5 & 0 & 5 & 54.19 & 0.62 & 2.20 & 0.08 & 28.09 & 0.34 \\
\hline 12 & CR7.5-NS5 & 7.5 & 5 & 28.06 & 0.40 & 1.43 & 0.09 & 15.07 & 0.17 \\
\hline 13 & CR15-NS5 & 15 & 5 & 16.99 & 0.19 & 1.23 & 0.10 & 7.63 & 0.04 \\
\hline
\end{tabular}

where CR: Crumb rubber, NS: Nano-silica, $\sigma_{\mathrm{c}}$ : Compressive strength, $\sigma_{\mathrm{f}}$ : Flexural tensile strength, $\sigma_{\mathrm{d}}$ : Direct tensile strength, ME: Modulus of Elasticity, PR: Poisson's Ratio.

\subsubsection{Statistical Models and Analysis of Variance}

A summary of the Analysis of Variance (ANOVA) for the quadratic response model is presented in Table 8. The F-values of the models were 113.91, 138.81, 285.63, 102.13, 765.52, and 73.58 for compressive strength, flexural tensile strength, direct tensile strength, drying shrinkage, ME, and PR, respectively. This indicated that the models were all significant. There was only $0.01 \%$ possibility that a model F-value of the respective magnitude could 
occur due to noise for all responses. Besides, the significance of all models and all their terms were verified using the $95 \%$ confidence interval $(p<0.05)$, as depicted in Table 8 .

Table 8. ANOVA for developed response models.

\begin{tabular}{|c|c|c|c|c|c|c|c|}
\hline Responses & Variables & SS & DF & $\mu^{2}$ & F-Values & $p$-Values Prob $>\mathrm{F}$ & Significant \\
\hline \multirow{7}{*}{$\begin{array}{l}\text { Compressive } \\
\text { Strength }\end{array}$} & Model & 2902.57 & 5 & 580.51 & 113.91 & $<0.0001$ & Yes \\
\hline & A-CR & 2638.45 & 1 & 2638.45 & 517.71 & $<0.0001$ & Yes \\
\hline & B-NS & 20.91 & 1 & 20.91 & 4.10 & 0.0825 & No \\
\hline & $\mathrm{AB}$ & 5.64 & 1 & 5.64 & 1.11 & 0.3277 & No \\
\hline & $\mathrm{A}^{2}$ & 193.72 & 1 & 193.72 & 38.01 & 0.0005 & Yes \\
\hline & $\mathrm{B}^{2}$ & 130.54 & 1 & 130.54 & 25.61 & 0.0015 & Yes \\
\hline & Lack of Fit & 18.61 & 3 & 6.20 & 1.45 & 0.3527 & No \\
\hline \multirow{7}{*}{$\begin{array}{l}\text { Flexural Tensile } \\
\text { Strength }\end{array}$} & Model & 0.52 & 5 & 0.10 & 138.81 & $<0.0001$ & Yes \\
\hline & $\mathrm{A}-\mathrm{CR}$ & 0.29 & 1 & 0.29 & 383.96 & $<0.0001$ & Yes \\
\hline & B-NS & 0.032 & 1 & 0.032 & 42.86 & 0.0003 & Yes \\
\hline & $\mathrm{AB}$ & $6.50 \times 10^{-4}$ & 1 & $6.50 \times 10^{-4}$ & 0.86 & 0.3836 & No \\
\hline & $\mathrm{A}^{2}$ & $6.53 \times 10^{-4}$ & 1 & $6.53 \times 10^{-4}$ & 0.87 & 0.3827 & No \\
\hline & $\mathrm{B}^{2}$ & 0.16 & 1 & 0.16 & 216.39 & $<0.0001$ & Yes \\
\hline & Lack of Fit & $2.17 \times 10^{-3}$ & 3 & $7.23 \times 10^{-4}$ & 0.93 & 0.5031 & No \\
\hline \multirow{7}{*}{$\begin{array}{l}\text { Direct Tensile } \\
\text { Strength }\end{array}$} & Model & 1.66 & 5 & 0.33 & 285.63 & $<0.0001$ & Yes \\
\hline & A-CR & 1.36 & 1 & 1.36 & 1172.76 & $<0.0001$ & Yes \\
\hline & B-NS & 0.022 & 1 & 0.022 & 19.15 & 0.0032 & Yes \\
\hline & $\mathrm{AB}$ & $2.72 \times 10^{-4}$ & 1 & $2.72 \times 10^{-4}$ & 0.23 & 0.6427 & No \\
\hline & $\mathrm{A}^{2}$ & 0.26 & 1 & 0.26 & 228.10 & $<0.0001$ & Yes \\
\hline & $\mathrm{B}^{2}$ & 0.081 & 1 & 0.081 & 69.74 & $<0.0001$ & Yes \\
\hline & Lack of Fit & $4.23 \times 10^{-3}$ & 3 & $1.41 \times 10^{-3}$ & 1.46 & 0.3527 & No \\
\hline \multirow{7}{*}{ Drying Shrinkage } & Model & $1.48 \times 10^{-3}$ & 5 & $2.96 \times 10^{-4}$ & 102.13 & $<0.0001$ & Yes \\
\hline & A-CR & $6.00 \times 10^{-4}$ & 1 & $6.00 \times 10^{-4}$ & 206.91 & $<0.0001$ & Yes \\
\hline & B-NS & $1.13 \times 10^{-4}$ & 1 & $1.13 \times 10^{-4}$ & 38.85 & 0.0004 & Yes \\
\hline & $\mathrm{AB}$ & 0.00 & 1 & 0.00 & 0.00 & 1.0000 & No \\
\hline & $\mathrm{A}^{2}$ & $3.80 \times 10^{-6}$ & 1 & $3.80 \times 10^{-6}$ & 1.31 & 0.2902 & No \\
\hline & $\mathrm{B}^{2}$ & $6.92 \times 10^{-4}$ & 1 & $6.92 \times 10^{-4}$ & 238.60 & $<0.0001$ & Yes \\
\hline & Lack of Fit & $7.10 \times 10^{-6}$ & 3 & $2.37 \times 10^{-6}$ & 0.72 & 0.5915 & No \\
\hline \multirow{7}{*}{$\begin{array}{l}\text { Modulus of } \\
\text { Elasticity }\end{array}$} & Model & 641.06 & 5 & 128.21 & 765.52 & $<0.0001$ & Yes \\
\hline & A-CR & 608.79 & 1 & 608.79 & 3634.91 & $<0.0001$ & Yes \\
\hline & B-NS & 1.55 & 1 & 1.55 & 9.26 & 0.0188 & Yes \\
\hline & $\mathrm{AB}$ & 0.12 & 1 & 0.12 & 0.71 & 0.4277 & No \\
\hline & $A^{2}$ & 30.23 & 1 & 30.23 & 180.51 & $<0.0001$ & Yes \\
\hline & $\mathrm{B}^{2}$ & 7.06 & 1 & 7.06 & 42.14 & 0.0003 & Yes \\
\hline & Lack of Fit & 0.28 & 3 & 0.095 & 0.43 & 0.7454 & No \\
\hline \multirow{7}{*}{ Poisson's Ratio } & Model & 0.16 & 5 & 0.032 & 73.58 & $<0.0001$ & Yes \\
\hline & A-CR & 0.15 & 1 & 0.15 & 345.32 & $<0.0001$ & Yes \\
\hline & B-NS & $8.05 \times 10^{-4}$ & 1 & $8.05 \times 10^{-4}$ & 1.84 & 0.2168 & No \\
\hline & $\mathrm{AB}$ & $3.06 \times 10^{-6}$ & 1 & $3.06 \times 10^{-6}$ & $7.01 \times 10^{-3}$ & 0.9356 & No \\
\hline & $A^{2}$ & $4.87 \times 10^{-3}$ & 1 & $4.87 \times 10^{-3}$ & 11.14 & 0.0124 & Yes \\
\hline & $\mathrm{B}^{2}$ & $7.47 \times 10^{-3}$ & 1 & $7.47 \times 10^{-3}$ & 17.1 & 0.0044 & Yes \\
\hline & Lack of Fit & $9.79 \times 10^{-4}$ & 3 & $3.26 \times 10^{-4}$ & 0.63 & 0.6344 & No \\
\hline
\end{tabular}

where SS: Sum of squares, DF: degree of freedom, $\mu^{2}$ : Mean square, F-values: Fisher statistical test values, $p$-values: Probability values, A: Crumb rubber, B: Nano-silica, $\mathrm{AB}$ : Interaction effects, $\mathrm{A}^{2}$ and $\mathrm{B}^{2}$ : Second order effect. 
The equations, in terms of coded factors, could be used to make predictions about the responses for the given levels of each factor. The high levels of the factors were coded as +1 and the low levels of the factors were coded as -1 . These equations were useful in detecting the relative impact of the factors by comparing the factor coefficients. The models' equation for predicting the mechanical strengths on the basis of variables are shown below, where ' $A$ ' and ' $B$ ' indicate the CR and NS in percentages, respectively.

$$
\begin{gathered}
\text { Compressive Strength }(\mathrm{MPa})=+36.24-20.97(A)-1.87(B)+1.19(A B)+8.38\left(A^{2}\right)-6.87\left(B^{2}\right) \\
\text { Flexural Tensile Strength }(\mathrm{MPa})=+0.73-0.22(A)-0.073(B)+0.013(A B)-0.015\left(A^{2}\right)-0.24\left(B^{2}\right) \\
\text { Direct Tensile Strength }(\mathrm{MPa})=+1.65-0.48(A)-0.016(B)+8.25 \times 10^{-3}(A B)+0.31\left(A^{2}\right)-0.17\left(B^{2}\right) \\
\text { Drying Shrinkage }(\%)=+0.071+0.010(A)+4.33 \times 10^{-3}(B)+0(A B)-1.17 \times 10^{-3}\left(A^{2}\right)+0.016\left(B^{2}\right) \\
\text { Modulus of Elasticity }(\mathrm{GPa})=+16.83-10.07(A)-0.51(B)-0.17(A B)+3.31\left(A^{2}\right)-1.60\left(B^{2}\right) \\
\text { Poisson's Ratio }=+0.22-0.16(A)-0.012(B)+8.75 \times 10^{-4}(A B)+0.042\left(A^{2}\right)-0.052\left(B^{2}\right)
\end{gathered}
$$

Referring to Table 9, Pred $R^{2}$ is a measure of how well the model predicts a response value, whereas Adj $R^{2}$ is for the number of parameters in the model relative to the number of points in the design. It is a measure of the amount of variation about the mean explained by the model. The Adj $R^{2}$ and Pred $R^{2}$ should be within approximately 0.20 of each other to be in reasonable agreement. If they are not, there may be a problem with either the data or the model. In this study, all responses were in good agreement. The inconsistency of the models with reference to the experimental data were checked using their SD values. The experimental data fitted the developed models with a higher degree of correlation because the $\mathrm{SD}$ values were lower as compared to the $\mu$ of the models. Besides, AP is a measure of the adequate signal. As they are greater than 4 , the developed models can be used for navigating the design space.

Table 9. Model validation for developed response models.

\begin{tabular}{ccccccc}
\hline Responses & SD & $\boldsymbol{\mu}$ & $\mathbf{R}^{\mathbf{2}}$ & Adj $\mathbf{R}^{\mathbf{2}}$ & Pred R $^{\mathbf{2}}$ & AP \\
\hline Compressive Strength & 2.26 & 36.93 & 0.99 & 0.98 & 0.93 & 32.27 \\
Flexural Tensile Strength & 0.03 & 0.61 & 0.99 & 0.98 & 0.96 & 39.83 \\
Direct Tensile Strength & 0.034 & 1.71 & 1 & 0.99 & 0.97 & 50.83 \\
Drying Shrinkage & $1.70 \times 10^{-3}$ & 0.077 & 0.99 & 0.98 & 0.94 & 34.72 \\
Modulus of Elasticity & 0.41 & 17.62 & 1 & 1 & 0.99 & 80.66 \\
Poisson's Ratio & 0.021 & 0.21 & 0.98 & 0.97 & 0.94 & 26.75 \\
\hline
\end{tabular}

where SD: Standard deviation, $\mu$ : Mean, $\mathrm{R}^{2}$ : Degree of correlation, Adj $\mathrm{R}^{2}$ : Adjusted the degree of correlation, Pred $\mathrm{R}^{2}$ : Predicted degree of correlation, AP: Adequate precision.

The diagnostics of the predicted response against the actual response values are shown in Figure 12. This type of graph helps to detect observations that are not well predicted by the model and the data points should be split evenly by $45^{\circ}$. As illustrated in Figure 12a-f, the experimental data were in good agreement and fitted to the predicted results from the models. Therefore, the developed response models were relevant and suitable for predicting the mechanical strengths and models of NS-CRM. 


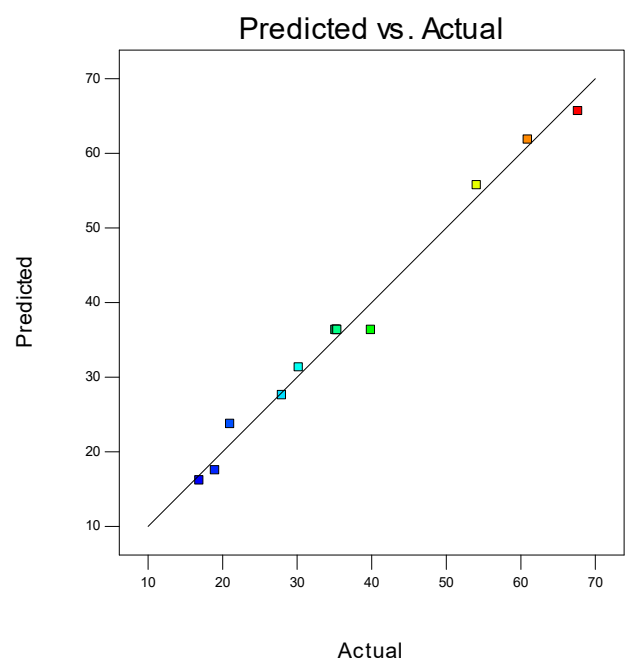

(a)

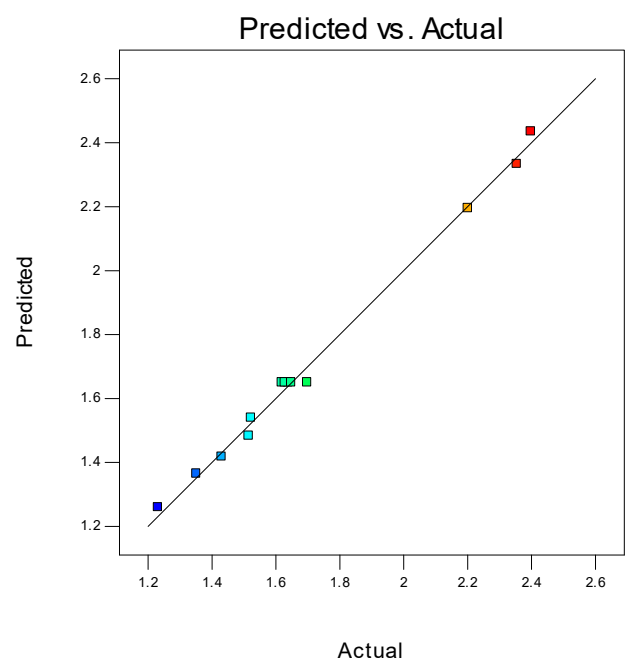

(c)

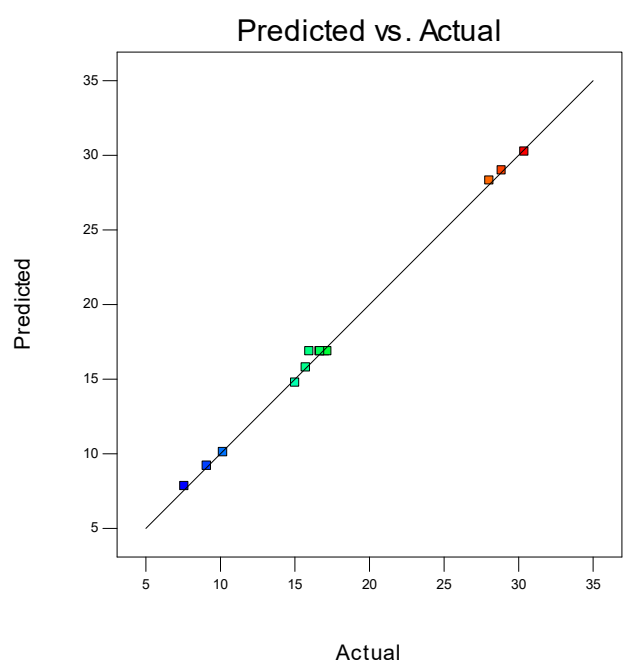

(e)

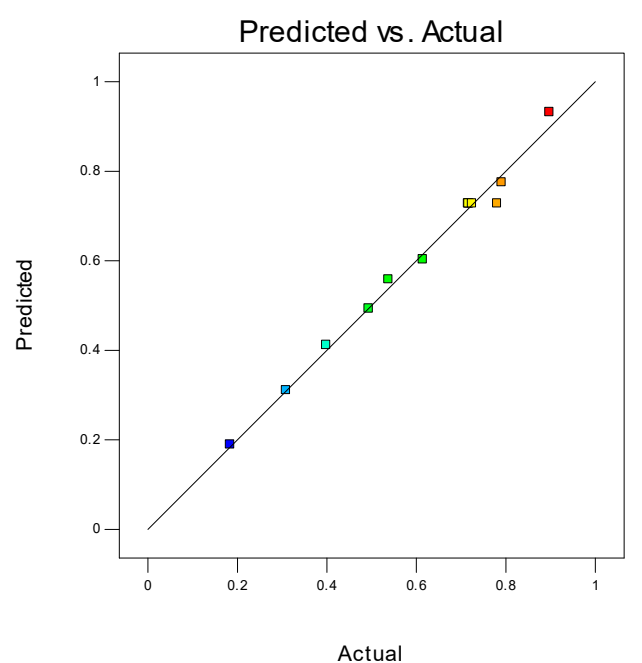

(b)

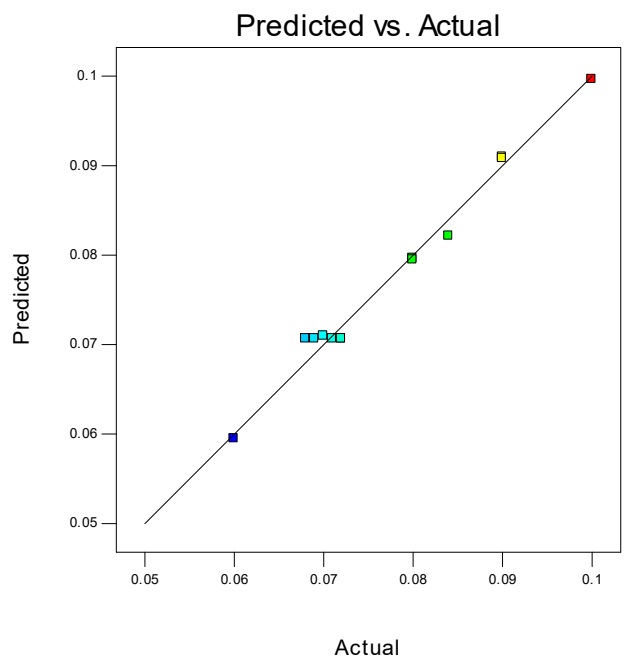

(d)

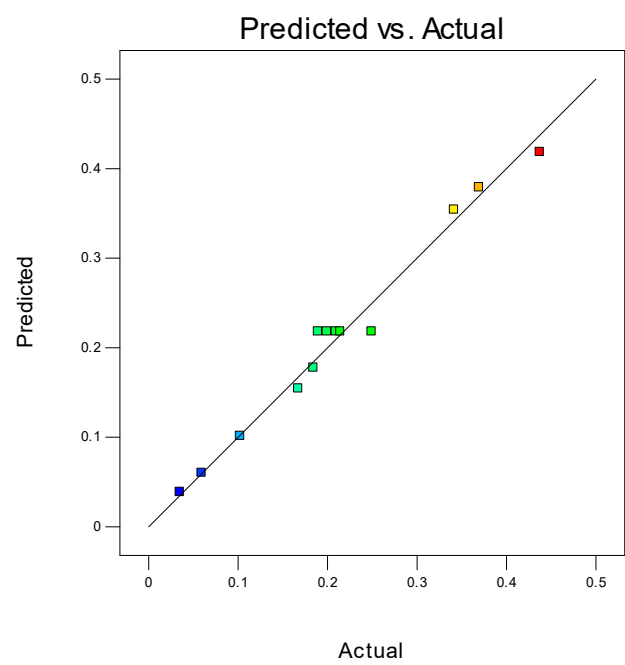

(f)

Figure 12. Predicted vs. actual plots for developed response models: (a) Compressive Strength; (b) Flexural Tensile Strength; (c) Direct Tensile Strength; (d) Drying Shrinkage; (e) Modulus of Elasticity; (f) Poisson's Ratio. 
A contour plot is a 2-dimensional (2D) representation of the response plotted against combinations of numeric factors and/or mixture components, as illustrated in Figure 13. It is able to illustrates the relationship between the responses, mixture components and/or numeric factors. Good interaction between variables and responses can be determined when the contour lines are oval in shape. As illustrated below, there were a perfect interaction between CR and NS for all the responses, with flexural tensile strength and drying shrinkage responses had the best interaction as shown in Figure 13b,d. The reddish areas on the contour plots showed the best combinations to give the optimum values, while the bluish area on the plot for drying shrinkage demonstrated the best.

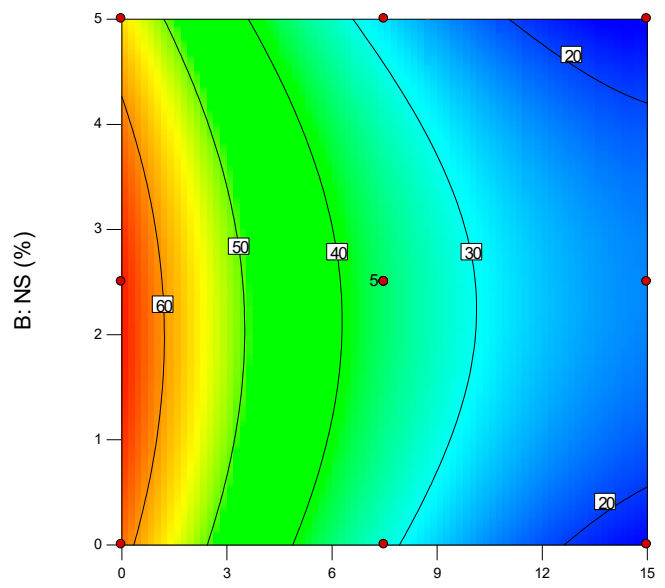

A: CR (\%)

(a)

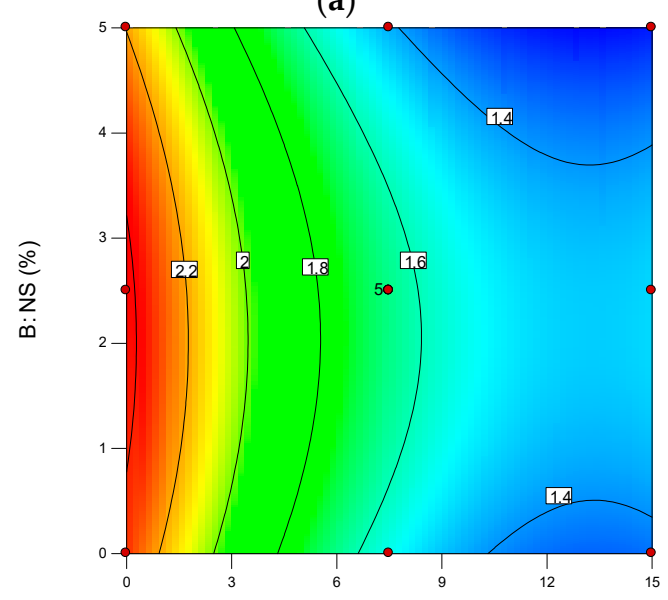

A: $C R(\%)$

(c)

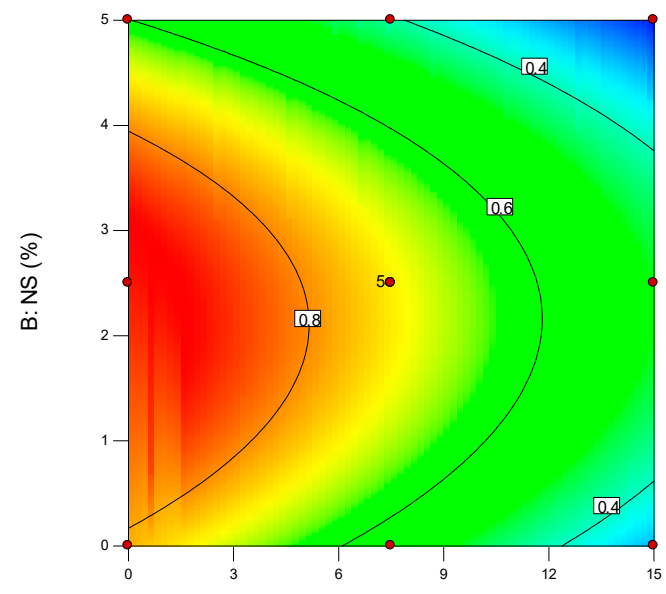

A: CR (\%)

(b)

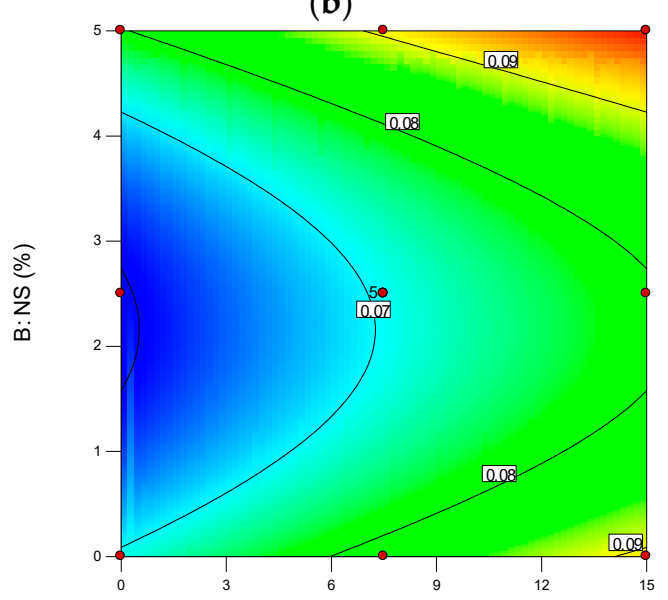

A: CR (\%)

(d)

Figure 13. Cont. 


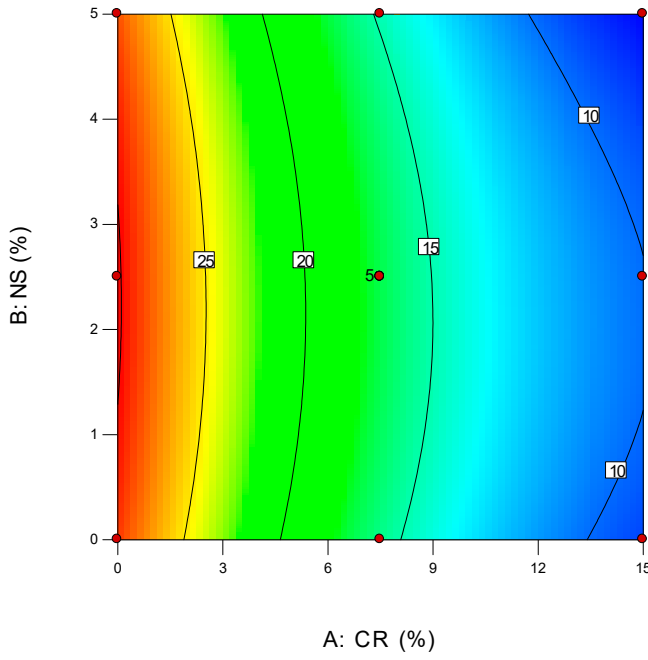

(e)

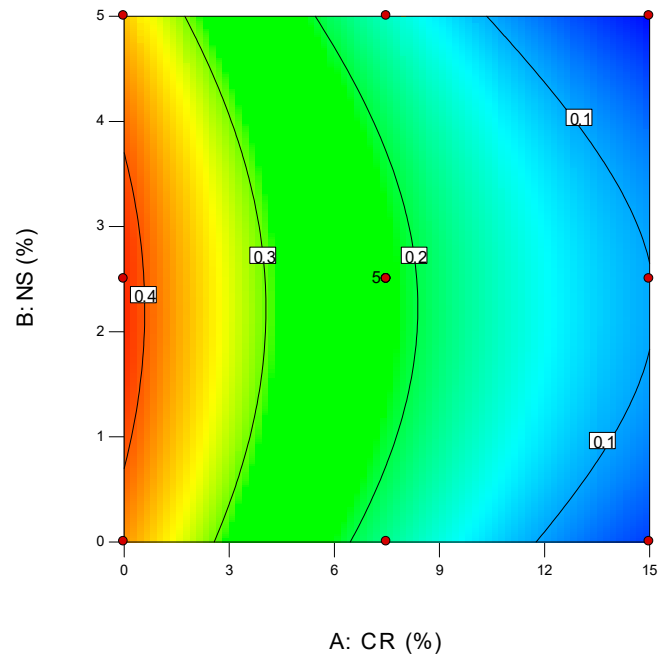

(f)

Figure 13. 2D contour plots for developed response models: (a) Compressive Strength; (b) Flexural Tensile Strength; (c) Direct Tensile Strength; (d) Drying Shrinkage; (e) Modulus of Elasticity; (f) Poisson's Ratio.

A 3-dimensional (3D) surface plot is a projection of the contour plot giving shape in addition to color and contour, as illustrated in Figure 14. It was observed that CR exhibited higher and negative effects on most of the responses as compared to NS.

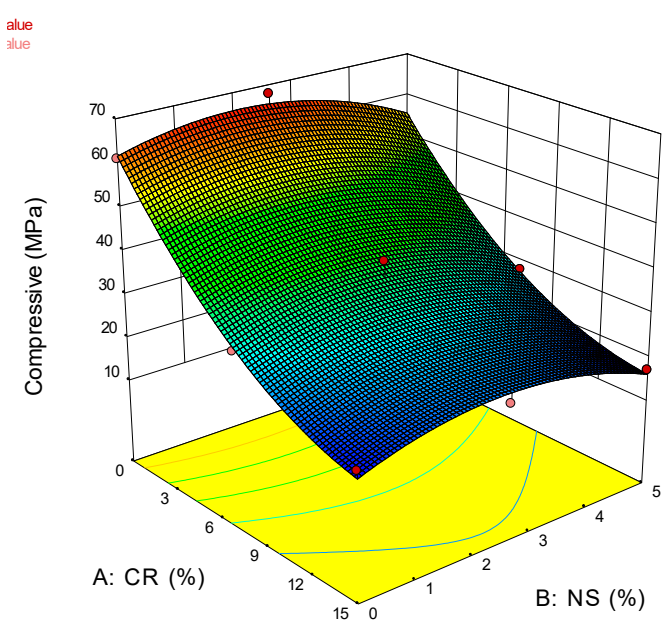

(a)

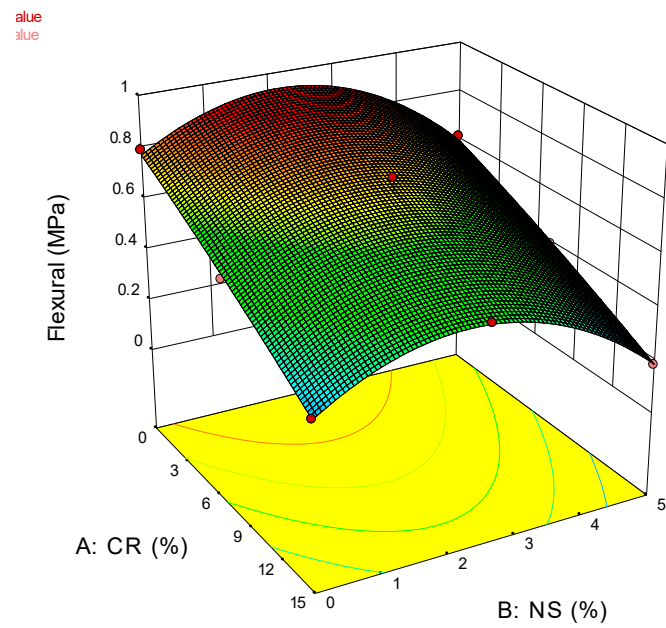

(b)

Figure 14. Cont. 


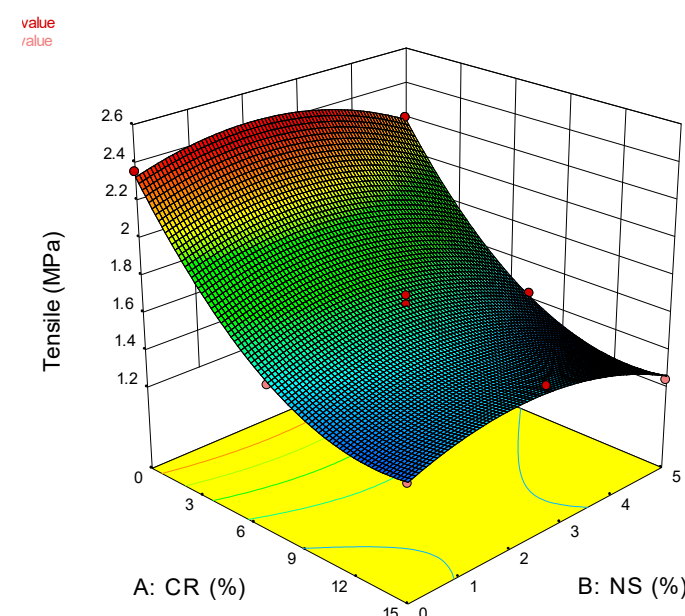

(c)

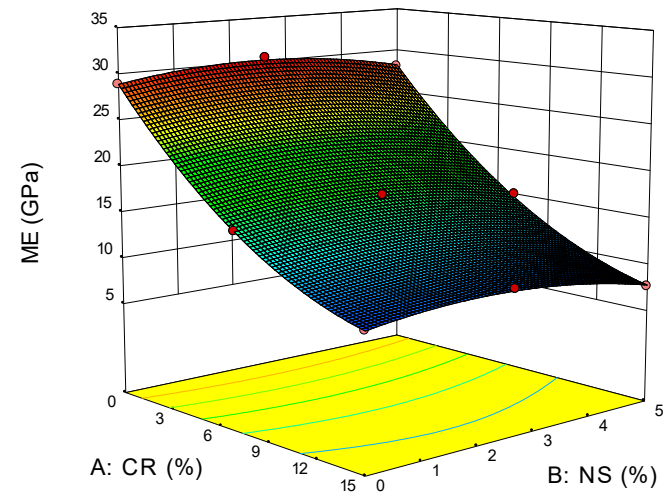

(e)

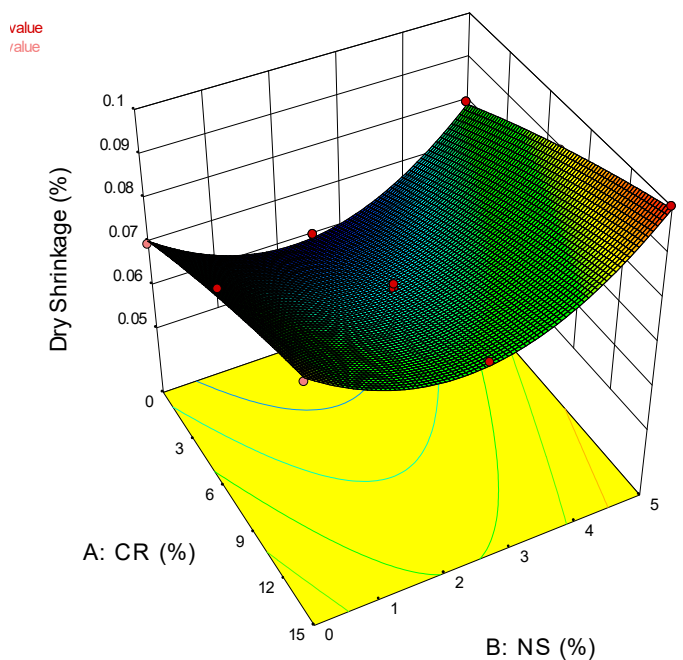

(d)

alue
auve

$\frac{\alpha}{\alpha}$

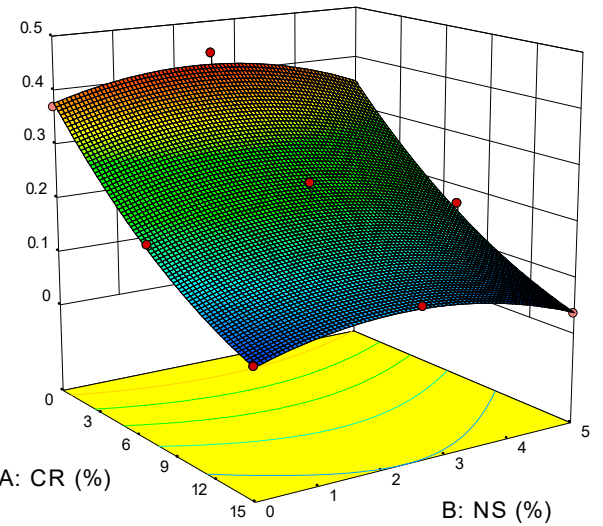

(f)

Figure 14. 3D contour plots for developed response models: (a) Compressive Strength; (b) Flexural Tensile Strength; (c) Direct Tensile Strength; (d) Drying Shrinkage; (e) Modulus of Elasticity; (f) Poisson's Ratio.

\subsubsection{Optimization and Experimental Validation}

Multi-objective optimization was carried out using the Central Composite Design (CCD) module in the Response Surface Methodology (RSM) tool to determine the optimum mixtures of NS-CRM that could produce the targeted compressive strength inputs, which were $20 \mathrm{MPa}$, $35 \mathrm{MPa}$, and $50 \mathrm{MPa}$. The variables and other responses were targeted to be in the range of lower and upper limits to ensure the CCD tool captured all possible combinations of results. The multi-objective optimization criteria are summarized in Table 10.

The results for the multi-objective optimization are shown in Table 11. Based on the optimization goals, the best mixture proportions selected by the CCD tool in RSM software were obtained by incorporating $12 \%, 8 \%$, and $3 \%$ of $\mathrm{CR}$ as a fine aggregate replacement and $5 \%, 3 \%$, and $2 \%$ of NS as replacement to cement to achieve $20 \mathrm{MPa}, 35 \mathrm{MPa}$, and $50 \mathrm{MPa}$ in compressive strength, with combined desirability of $100 \%$ as shown in Table 11 and Figure 15. 
Table 10. Multi-objective optimization criteria.

\begin{tabular}{ccc}
\hline Variables and Responses & Goals & Lower Limits \\
\hline Crumb Rubber (\%) & In Range & 0 \\
Nano-Silica (\%) & In Range & 0 \\
Compressive Strength (MPa) & Target: 20, 35, 50 MPa & 15 \\
Flexural Tensile Strength (MPa) & In Range & 5 \\
Direct Tensile Strength (MPa) & In Range & 67.77 \\
Drying Shrinkage (\%) & In Range & 0.99 \\
Modulus of Elasticity (GPa) & In Range & 1.23 \\
Poisson's Ratio & In Range & 0.06 \\
\hline
\end{tabular}

Table 11. NS-CRM models verification.

\begin{tabular}{|c|c|c|c|c|c|c|c|}
\hline Mix & Validation & $\sigma_{\mathrm{c}}(\mathrm{MPa})$ & $\sigma_{\mathrm{f}}(\mathrm{MPa})$ & $\sigma_{\mathrm{d}}(\mathrm{MPa})$ & DS (\%) & ME (GPa) & PR \\
\hline \multirow{3}{*}{ CR12-NS5 } & Predicted & 20.00 & 0.330 & 1.282 & 0.093 & 10.159 & 0.085 \\
\hline & Experimental & 19.58 & 0.322 & 1.249 & 0.091 & 9.894 & 0.083 \\
\hline & Error $(\%)$ & 2.10 & 2.42 & 2.57 & 2.68 & 2.61 & 2.58 \\
\hline \multirow{3}{*}{ CR8-NS3 } & Optimization & 35.00 & 0.698 & 1.616 & 0.072 & 16.365 & 0.208 \\
\hline & Experimental & 34.25 & 0.679 & 1.581 & 0.071 & 15.998 & 0.203 \\
\hline & Error (\%) & 2.14 & 2.72 & 2.17 & 2.07 & 2.24 & 2.40 \\
\hline \multirow{3}{*}{ CR3-NS2 } & Optimization & 50.00 & 0.845 & 1.995 & 0.065 & 23.176 & 0.315 \\
\hline & Experimental & 48.96 & 0.826 & 1.955 & 0.063 & 22.623 & 0.307 \\
\hline & Error $(\%)$ & 2.08 & 2.25 & 2.01 & 2.63 & 2.39 & 2.54 \\
\hline
\end{tabular}

where CR: Crumb rubber, NS: Nano-silica, $\sigma_{\mathrm{c}}$ : Compressive strength, $\sigma_{\mathrm{f}}$ : Flexural tensile strength, $\sigma_{\mathrm{d}}$ : Direct tensile strength, DS: Drying shrinkage, ME: Modulus of Elasticity, PR: Poisson's Ratio.

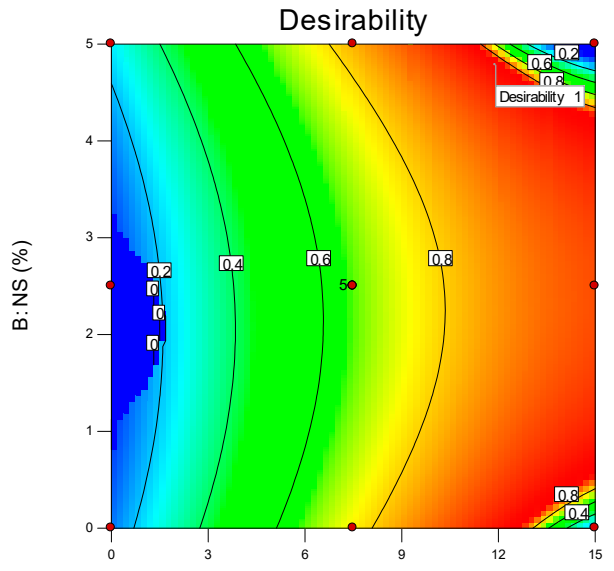

A: CR $(\%)$

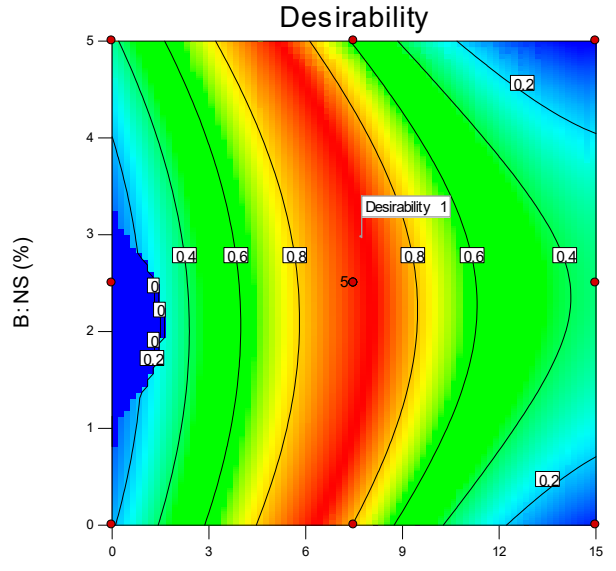

A: CR (\%)

(a)

(b)

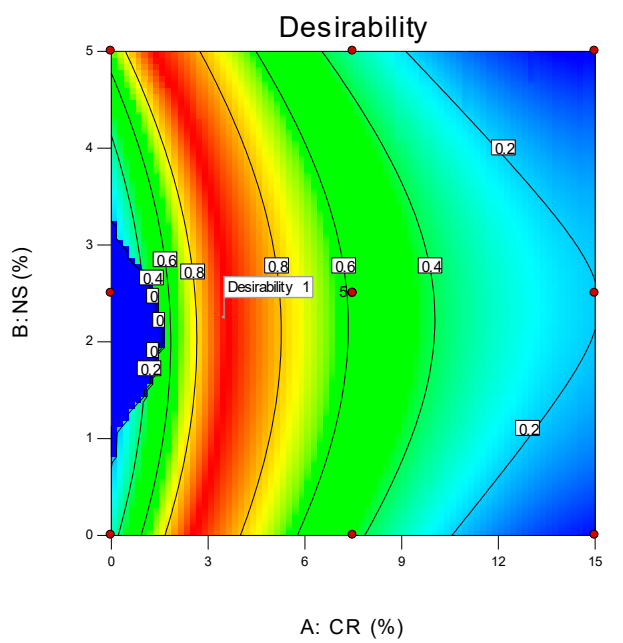

(c)

Figure 15. Desirable compressive strength of NS-CRM: (a) $20 \mathrm{MPa}$; (b) $35 \mathrm{MPa}$; (c) $50 \mathrm{MPa}$. 
An experimental validation study was carried out using the optimized mix proportions produced by CCD tool in RSM in order to validate the optimization results and the overall response models. The compressive strength, flexural tensile strength, direct tensile strength, drying shrinkage, ME, and PR were then tested experimentally after 28 days of curing, and the results were compared with the predicted values given by CCD tool in the RSM. The percentage errors between the predicted responses and the experimental results were calculated using Equation (7) below. A summary of the experimental and predicted results is illustrated in Table 11. The experimental and the predicted values were in good agreement with one another, with calculated errors of $2 \%$ to $3 \%$ for all responses of NS-CRM.

$$
\text { Error }(\%)=\left|\frac{\text { Experimental }- \text { Predicted }}{\text { Experimental }}\right| \times 100
$$

\subsection{Microstructural Analysis of NS-CRM}

\subsubsection{Scanning Electron Microscope}

Scanning Electron Microscope (SEM) image analysis can reveal detailed size, shape, and structural nanomaterial information because it can achieve a resolution better than $1 \mathrm{~nm}$. For this study, three crushed samples were sent to the laboratory for testing, which included CR7.5-NS0, CR7.5-NS2.5, and CR7.5-NS5. In order to prove that NS could act as a filler in filling the voids created between the cement matrix and CR, the samples provided had the same percentage of CR but varied percentages of NS.

\section{CR7.5-NS0}

Figure 16 shows the microstructure and Energy Dispersive X-Ray Spectroscopy (EDX) images of sample CR7.5-NS0. Based on the image analysis produced, ITZ created between the cement matrix and CR was $4.598 \mu \mathrm{m}$. It confirmed that the mixture containing only $\mathrm{CR}$ had higher air content due to the non-polar nature of CR particles. Mohammed et al. [64] stated that $C R$ has the tendency to repel water and entrap air on its rough surface, hence causing ITZ to be created. This causes the bonding between CR and cement paste formed in hardened mortar to be weakened due to less adhesion of the mortar matrix. According to Hunag et al. [65], the interface gaps between CR and grout can be seen clearly because $\mathrm{CR}$ is a type of organic high molecular weight material. The bonding between material interfaces is weak when it is added into the cement mixture. Therefore, the material interfaces are likely to be damaged when the specimen is under an external force. Supported by Su et al. [66], the failure of samples is primarily caused by debonding between the aggregates and the cement paste. Incorporating CR particles results in a weaker bond between the $C R$ and the surrounding cement paste. It is proven that the adhesion between the $\mathrm{CR}$ particles and the cement matrix was poor.

\section{CR7.5-NS2.5}

Figure 17 shows the microstructure and EDX images of sample CR7.5-NS2.5. Based on the image analysis produced, ITZ created between the cement matrix and CR was $2.004 \mu \mathrm{m}$. Mohammed et al. [67] stated that incorporating NS into the mixture will refine the size of pores and densify the ITZ between cement matrix and CR. NS has high pozzolanic reactivity where it reacts with excess calcium hydrate $(\mathrm{CH})$ and produces more $\mathrm{C}-\mathrm{S}-\mathrm{H}$ gel which fills up the pores in the cement matrix. It confirmed that NS was able to increase the density, reduce porosity and improve the bonding between CR and cement paste. At the same time, it enhances the durability as well as the strengths of cement composites. Thus, the ITZ thickness created decreases due to the physico-chemical effect of NS. According to Liu et al. [20], the microstructure of the ITZ between aggregate and the cement paste appears to be denser with the presence of NS. The improvement in the ITZ microstructure is probably due to the reaction between NS and $\mathrm{CH}$ which combine some water in their products and reduce the porosity of ITZ. Supported by Jaishankar [22], the pozzolanic reaction densifies the microstructures by turning $\mathrm{CH}$ into secondary C-S-H and produces a more homogeneous microstructure. No large pores are easily found and therefore, it is 
expected that the mechanical and durable properties of the samples can be improved due to this densified ITZ, which is normally the weakest part in cement composites.

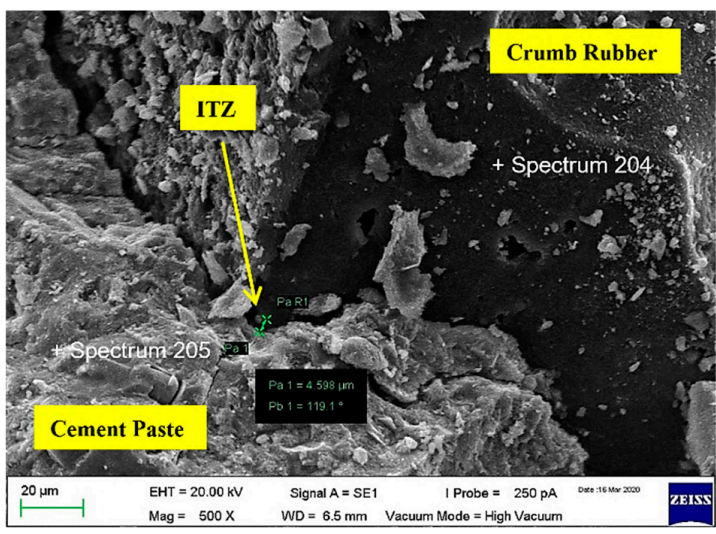

(a)

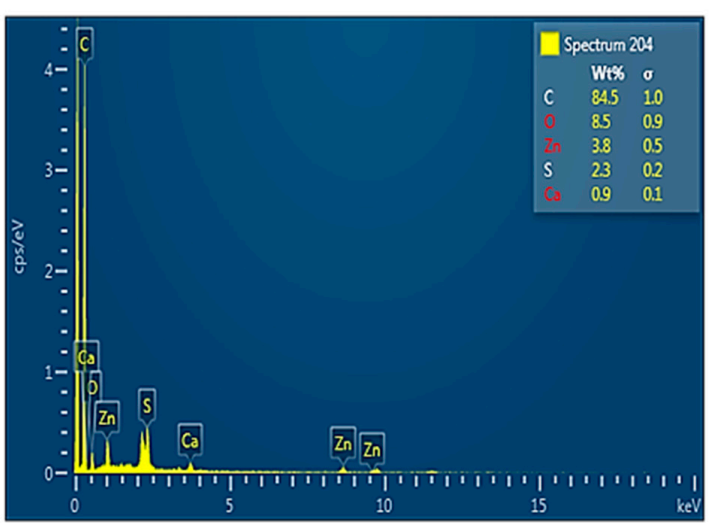

(b)

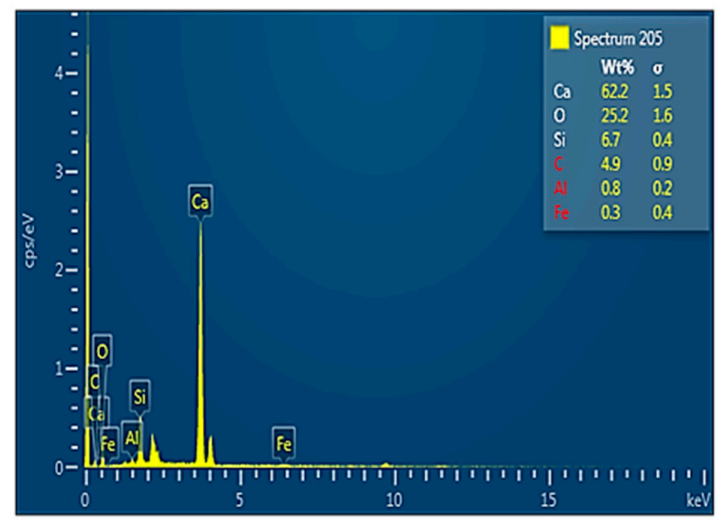

(c)

Figure 16. CR7.5-NS0 sample: (a) Microstructure ITZ = $4.598 \mu \mathrm{m}$; (b) EDX of crumb rubber; (c) EDX of cement.

\section{CR7.5-NS5}

Figure 18 shows the microstructure and EDX images for sample CR7.5-NS5. Based on the image analysis produced, ITZ created between the cement matrix and CR was $8.128 \mu \mathrm{m}$. Li et al. [59] stated that incorporating NS into a mixture will refine the size of the pores and densify the ITZ between cement matrix and CR. However, it is important to note that when a high percentage of NS is used, it can actually decrease the strength of the composite instead of improving it. This is due to the difficulty of NS to disperse uniformly when excessive NS is used. Hence, a weak zone is created in the form of voids; consequently, a homogenous hydrated microstructure cannot be formed. Thus, the ITZ thickness created was larger as compared to a mix design containing $2.5 \%$ of NS. Supported by Faez et al. [68], when the use of NS seems to be high in combination with the free lime produced in the hydration process, this causes the strength to decrease. The unreacted NS does not help the strength to increase and leads to defect in strength. Another reason is that NS tends to become bulky and agglomerate because of its high surface energy. Therefore, the percentage of NS which is more than the required amount results in uneven distribution, and NS appears as weak mass regions. Likewise, Mohammed et al. [69] stated that too much NS gives an adverse effect on the hardened mixture, and NS particles tend to coagulate because they exceed the limit that $\mathrm{CH}$ can accommodate. 


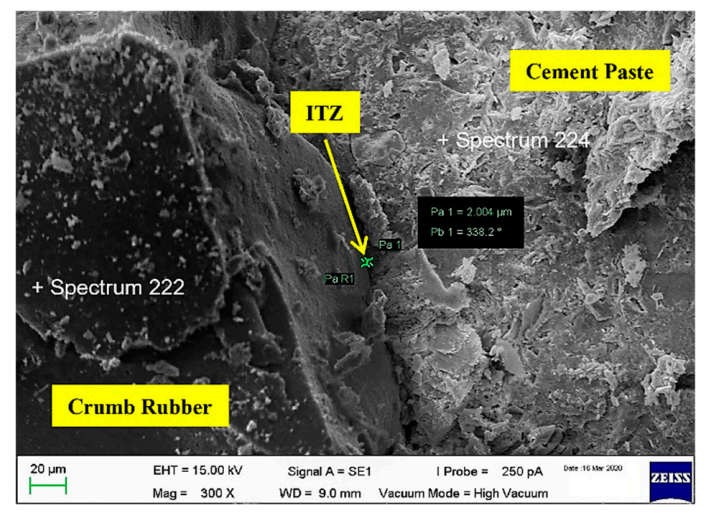

(a)

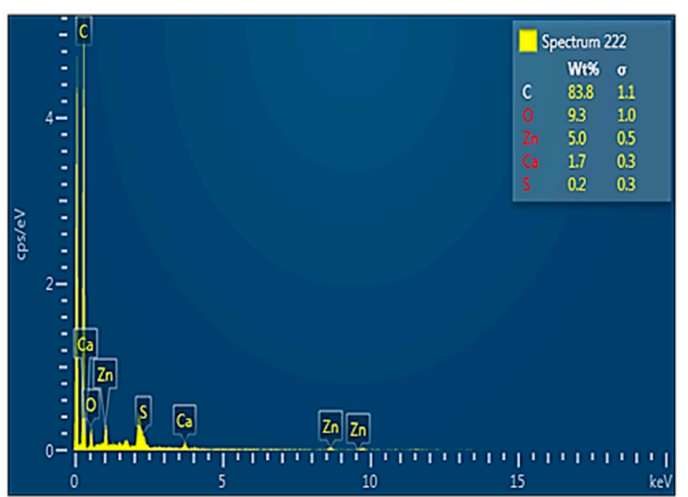

(b)

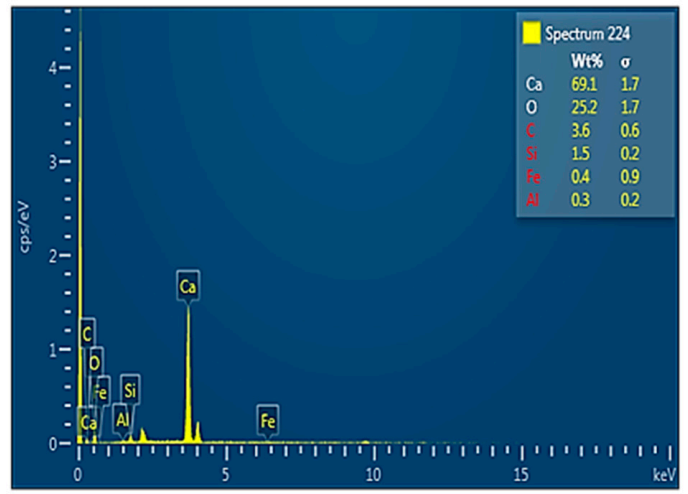

(c)

Figure 17. CR7.5-NS2.5 sample. (a) Microstructure ITZ = $2.004 \mu \mathrm{m}$; (b) EDX of crumb rubber; (c) EDX of cement.

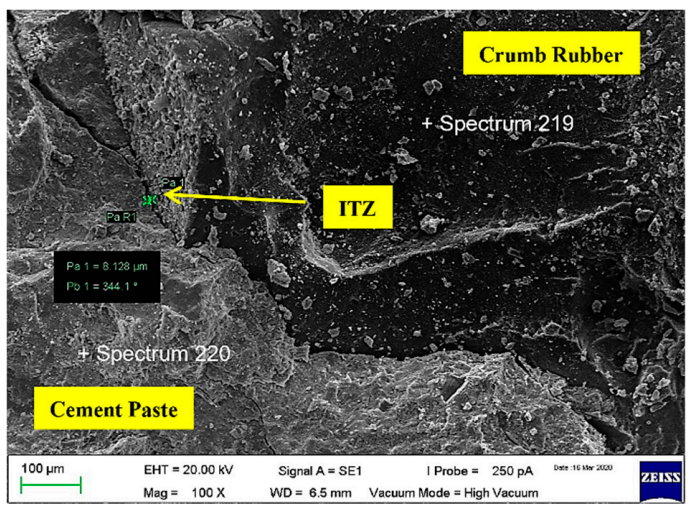

(a)

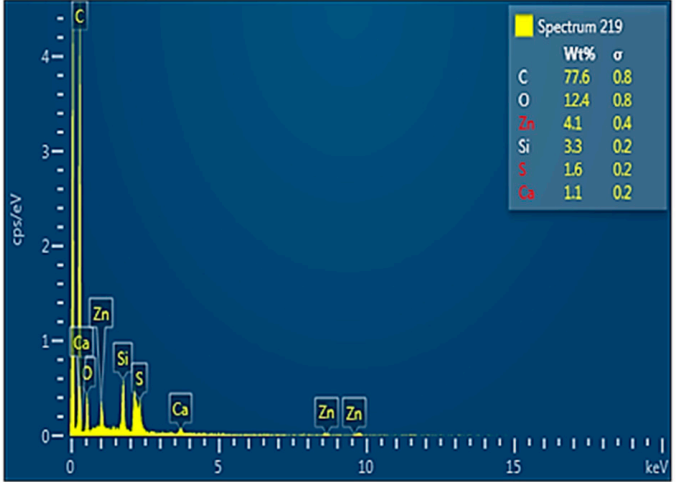

(b)

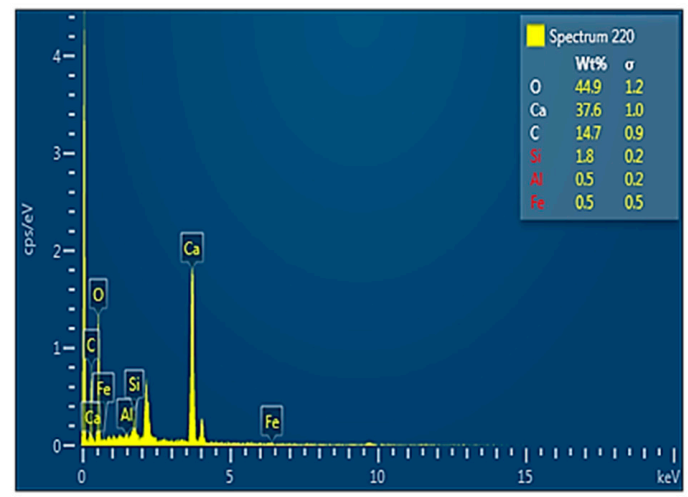

(c)

Figure 18. CR7.5-NS5 sample. (a) Microstructure ITZ = 8.128 $\mu \mathrm{m}$; (b) EDX of crumb rubber; (c) EDX of cement. 


\subsubsection{Mercury Intrusion Porosimetry}

Mercury Intrusion Porosimetry (MIP) test was used to study the effect of physicochemical reaction of NS on CRM. The presence of NS results in the improvement of pore structure in the hardened matrix of CRM by filling the voids of ITZ, thereby breaking the interconnectivity, and decreasing its diameter. Figure 19 illustrates the pore size distribution of samples CR7.5-NS0, CR7.5-NS2.5, and CR7.5-NS5. Based on the graph plotted, the pore diameter for CR7.5-NS0 and CR7.5-NS2.5 ranged from $7 \mathrm{~nm}$ to $83,000 \mathrm{~nm}$ whereas for CR7.5-NS5 ranged from $10 \mathrm{~nm}$ to 100,000 nm. Evidently, a mix design with the highest percentage of NS recorded the highest cumulative pore volume as compared to the other two mix designs. Agreed by Li et al. [70] and Du et al. [71], the higher pore volume in the pore size distribution shows that the mixture contains higher porosity and permeability, as permeability is control by large capillaries. According to Mohammed and Adamu [72], the addition of NS further reduces the total pore volumes of the mixture. The total pore volume of mixes containing NS is found to decrease compared to the one without NS. As stated by Mohammed and Azmi [73], this is due to the ability of NS to densify and improve the pore structure of the mixture up to nano-size due to the increase in the pozzolanic reaction between silicon dioxide $\left(\mathrm{SiO}_{2}\right)$ and unreacted $\mathrm{Ca}(\mathrm{OH})_{2}$ from cement hydration products to produce more C-S-H gels. As explained by Mohammed et al. [74], the high porosity of ITZ can be lessened through physico-chemical effects, while increasing the C-S-H gel and filling up of nano-pores will result in the improvement of the ITZ and reducing pore size. The hardened specimens are interconnected, therefore, and incorporating NS helps in decreasing the total pore volume and consequently reducing the porosity.

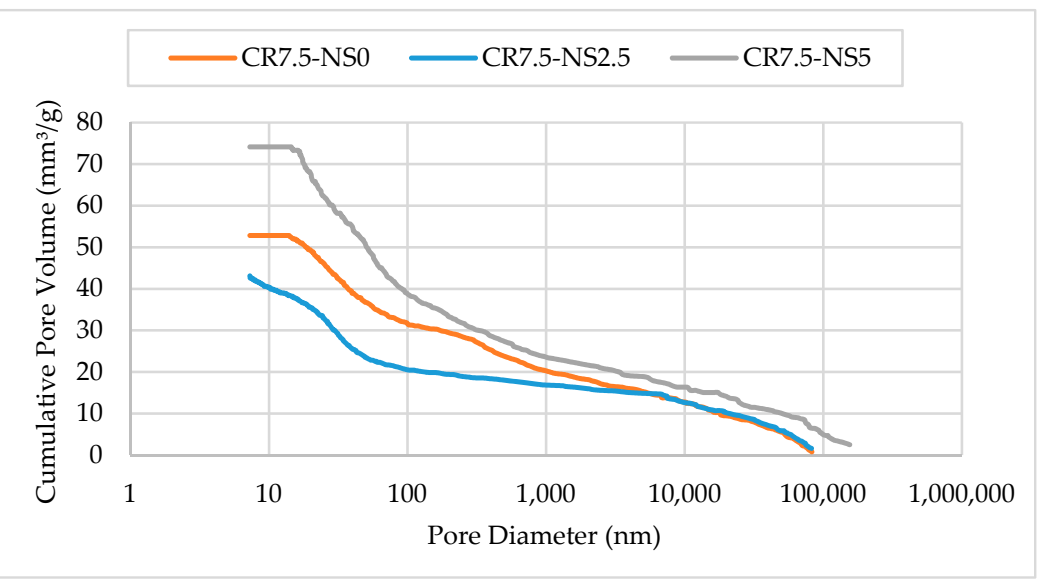

Figure 19. Pore size distribution of NS-CRM samples.

\section{Conclusions}

The following conclusions are drawn based on the experiments and analysis results.

1. The compressive strength, flexural tensile strength, direct tensile strength, Modulus of Elasticity (ME), and Poisson's Ratio (PR) of crumb rubber mortar containing nanosilica (NS-CRM) decreased as the percentage of crumb rubber (CR) was increased. However, an increase in drying shrinkage and porosity of NS-CRM was observed. This is attributed to the hydrophobic properties of CR which causes an increment of voids in the mixture.

2. The compressive strength, flexural tensile strength, direct tensile strength, ME, and PR of NS-CRM increased when $2.5 \%$ of nano-silica (NS) was incorporated. However, a decrease in drying shrinkage and porosity of NS-CRM was observed. This is attributed to the pozzolanic reaction of NS and its nanoparticle size.

3. The mechanical properties of NS-CRM acted contrariwise when $5 \%$ of NS was incorporated. This is attributed to the difficulty of NS to disperse uniformly when excessive NS is used. Hence, a weak zone is created in form of voids; consequently, the homogenous hydrated microstructure cannot be formed. 
4. The models developed using RSM for predicting the mechanical strengths of NS-CRM were acceptable, with errors less than $5 \%$.

5. The interfacial transition zone (ITZ) and cumulative pore volume of CRM were improved with the presence of NS. This is attributed to the physico-chemical effect of NS. However, a high percentage of NS causes the mesopores volume to increase due to agglomeration of unreacted NS which leads to excessive self-desiccation.

Author Contributions: Conceptualization, S.S., B.S.M. and M.S.L.; methodology, S.S., B.S.M. and M.M.A.W.; software, S.S.; validation, S.S.; formal analysis, S.S., B.S.M. and M.M.A.W.; investigation, S.S.; resources, M.M.A.W.; writing—original draft preparation, S.S. and B.S.M.; writing-review and editing, S.S. and B.S.M.; supervision, B.S.M., M.M.A.W. and M.S.L.; project administration, B.S.M. and M.S.L.; funding acquisition, B.S.M. All authors have read and agreed to the published version of the manuscript.

Funding: This research was funded by Yayasan UTP (YUTP) with grant code YUTP 015LC0-097.

Institutional Review Board Statement: Not applicable.

Informed Consent Statement: Not applicable.

Data Availability Statement: The data presented in this study are available on request from the corresponding author, B.S.M. The data are not publicly available due to them containing information that could compromise the privacy of research of the first author, S.S.

Acknowledgments: The authors would like to thank Universiti Teknologi Petronas (UTP) Malaysia for supporting the project.

Conflicts of Interest: The authors declare no conflict of interest.

\section{References}

1. Pathak, S.K.; Sood, V.; Singh, Y.; Channiwala, S. Real World Vehicle Emissions: Their Correlation with Driving Parameters. Transp. Res. Part D Transp. Environ. 2016, 44, 157-176. [CrossRef]

2. Azevedo, F.; Pacheco-Torgal, F.; Jesus, C.; de Aguiar, J.B.; Camões, A. Properties and Durability of HPC with Tyre Rubber Wastes. Constr. Build. Mater. 2012, 34, 186-191. [CrossRef]

3. Demir, F.; Yesilata, B.; Turgut, P.; Bulut, H.; Isiker, Y. Investigation of The Effects of pH, Aging and Scrap Tire Content on The Dissolution Behaviors of New Scrap Tire-Concrete Mixture Structures. J. Clean. Prod. 2015, 93, 38-46. [CrossRef]

4. Liu, F.; Li, L.-J.; Xie, W.-F.; Chen, Z.-Z. Experimental Study of Recycled Rubber-Filled High-Strength Concrete. Mag. Concr. Res. 2009, 61, 549-556. [CrossRef]

5. Sukontasukkul, P. Use of Crumb Rubber to Improve Thermal and Sound Properties of Pre-Cast Concrete Panel. Constr. Build. Mater. 2008, 23, 1084-1092. [CrossRef]

6. Siddique, R.; Naik, T.R. Properties of Concrete Containing Scrap-Tire Rubber-An Overview. Waste Manag. 2004, 24, 563-569. [CrossRef]

7. Youssf, O.; El Gawady, M.; Mills, J.; Ma, X. An Experimental Investigation of Crumb Rubber Concrete Confined by Fibre Reinforced Polymer Tubes. Constr. Build. Mater. 2014, 53, 522-532. [CrossRef]

8. Liu, F.; Meng, L.-Y.; Ning, G.-F.; Li, L. Fatigue Performance of Rubber-Modified Recycled Aggregate Concrete (RRAC) for Pavement. Constr. Build. Mater. 2015, 95, 207-217. [CrossRef]

9. Eldin, N.N.; Senouci, A.B. Rubber-Tire Particles as Concrete Aggregate. J. Mater. Civ. Eng. 1993, 5, 478-496. [CrossRef]

10. Topçu, I.B. The Properties of Rubberized Concretes. Cem. Concr. Res. 1995, 25, 304-310. [CrossRef]

11. Malik, N.H.; Al-Arainy, A.A.; Qureshi, M.I. Electrical Insulation in Power Systems; CRC Press: Boca Raton, FL, USA, 2018. [CrossRef]

12. Hernández-Olivares, F.; Barluenga, G. Fire Performance of Recycled Rubber-Filled High-Strength Concrete. Cem. Concr. Res. 2004, 34, 109-117. [CrossRef]

13. Fattuhi, N.; Clark, L. Cement-Based Materials Containing Shredded Scrap Truck Tyre Rubber. Constr. Build. Mater. 1996, 10, 229-236. [CrossRef]

14. Raghavan, D.; Huynh, H. Workability, Mechanical Properties, and Chemical Stability of a Recycled Tyre Rubber-Filled Cementitious Composite. J. Mater. Sci. 1998, 33, 1745-1752. [CrossRef]

15. Wongsa, A.; Sata, V.; Nematollahi, B.; Sanjayan, J.; Chindaprasirt, P. Mechanical and Thermal Properties of Lightweight Geopolymer Mortar Incorporating Crumb Rubber. J. Clean. Prod. 2018, 195, 1069-1080. [CrossRef]

16. Yu, Y.; Zhu, H. Influence of Rubber Size on Properties of Crumb Rubber Mortars. Materials 2016, 9, 527. [CrossRef] [PubMed]

17. Angelin, A.F.; Andrade, M.F.; Bonatti, R.; Lintz, R.C.C.; Gachet-Barbosa, L.A.; Osório, W.R. Effects of Spheroid and Fiber-Like Waste-Tire Rubbers on Interrelation of Strength-To-Porosity in Rubberized Cement and Mortars. Constr. Build. Mater. 2015, 95, 525-536. [CrossRef] 
18. Herrero, S.; Mayor, P.; Hernández-Olivares, F. Influence of Proportion and Particle Size Gradation of Rubber from End-of-Life Tires on Mechanical, Thermal and Acoustic Properties of Paster-rubber Mortars. Mater. Des. 2013, 47, 633-642. [CrossRef]

19. Gopinath, S.; Mouli, P.; Murthy, A.; Iyer, N.; Maheswaran, S. Effect of Nano Silica on Mechanical Properties and Durability of Normal Strength Concrete. Arch. Civ. Eng. 2012, 58, 433-444. [CrossRef]

20. Liu, J.; Li, Q.; Xu, S. Influence of Nanoparticles on Fluidity and Mechanical Properties of Cement Mortar. Constr. Build. Mater. 2015, 101, 892-901. [CrossRef]

21. Lieftink, D.; Dekker, B.; Geus, J. The Structure of Silica Particles Prepared by Acid Treatment of Olivine: A Nitrogen-Physisorption and 29Si-MAS NMR Study. In Studies in Surface Science and Catalysis; Elsevier: Amsterdam, The Netherlands, 1998; Volume 118, pp. 755-761. [CrossRef]

22. Jaishankar, P.; Kanchidurai, S.; Mohan, K.S.R. Durability and Pore Structure Analysis of High-Performance Concrete with Nano Silica. Rom. J. Mater. 2020, 50, 478-484.

23. Roddy, C.W.; Chatterji, J.; Cromwell, R. Well Treatment Composition and Methods Utilizing Nano-Particles. U.S. Patent 7,559,369, 14 July 2009.

24. Ghanbari, M.; Kohnehpooshi, O.; Tohidi, M. Experimental Study of the Combined Use of Fiber and Nano Silica Particles on the Properties of Lightweight Self Compacting Concrete. Int. J. Eng. 2020, 33, 1499-1511. [CrossRef]

25. Sakka, S.; Kozuka, H. Handbook of Sol-Gel Science and Technology: Processing, Characterization and Applications; Kluwer Academic Publishers: Boston, MA, USA, 2005.

26. Sadrmomtazi, A.; Fasihi, A.; Balalaei, F.; Haghi, A.K. Investigation of Mechanical and Physical Properties of Mortars Containing Silica Fume and Nano-SiO 2 . In Proceedings of the International Conference on Concrete and Development, Tehran, Iran, 27-28 April 2009.

27. Qing, Y.; Zenan, Z.; Deyu, K.; Rongshen, C. Influence of Nano-SiO ${ }_{2}$ Addition on Properties of Hardened Cement Paste as Compared with Silica Fume. Constr. Build. Mater. 2007, 21, 539-545. [CrossRef]

28. Li, H.; Xiao, H.-G.; Ou, J.-P. A Study on Mechanical and Pressure-Sensitive Properties of Cement Mortar with Nanophase Materials. Cem. Concr. Res. 2004, 34, 435-438. [CrossRef]

29. American's Cement Manufacturer. Portland Cement Association. 2019. Available online: https://www.cement.org/cementconcrete-applications / concrete-materials / cement-types (accessed on 15 October 2020).

30. Aleem, S.A.E.; Heikal, M.; Morsi, W. Hydration Characteristic, Thermal Expansion and Microstructure of Cement Containing Nano-Silica. Constr. Build. Mater. 2014, 59, 151-160. [CrossRef]

31. ASTM International. ASTM C144-18, Standard Specification for Aggregate for Masonry Mortar; ASTM International: West Conshohocken, PA, USA, 2018.

32. Nacif, G.L.; Panzera, T.; Strecker, K.; Christoforo, A.L.; Paine, K. Investigations on Cementitious Composites Based on Rubber Particle Waste Additions. Mater. Res. 2012, 16, 259-268. [CrossRef]

33. ASTM International. ASTM C1602/C1602M-18, Standard Specification for Mixing Water Used in the Production of Hydraulic Cement Concrete; ASTM International: West Conshohocken, PA, USA, 2018.

34. Bradley, N. The Response Surface Methodology. Ph.D. Thesis, Indiana University South Bend, South Bend, IN, USA, 2007.

35. Carley, K.M.; Kamneva, N.Y.; Reminga, J. Response Surface Methodology; Technical Report; Carnegie-Mellon University: Pittsburgh, PA, USA, 2004.

36. Kütahyalı, C.; Çetinkaya, B.; Acar, M.B.; Işık, N.O.; Cireli, I. Investigation of Strontium Sorption onto Kula Volcanics Using Central Composite Design. J. Hazard. Mater. 2012, 201-202, 115-124. [CrossRef]

37. Kütahyalı, C.; Sert, Ş.; Cetinkaya, B.; Yalçıntaş, E.; Acar, M.B. Biosorption of Ce(III) onto Modified Pinus Brutia Leaf Powder Using Central Composite Design. Wood Sci. Technol. 2011, 46, 721-736. [CrossRef]

38. ASTM International. ASTM C136/C136M-19, Standard Test Method for Sieve Analysis of Fine and Coarse Aggregates; ASTM International: West Conshohocken, PA, USA, 2019.

39. ASTM International. ASTM C1437-13, Standard Test Method for Flow of Hydraulic Cement Mortar; ASTM International: West Conshohocken, PA, USA, 2013.

40. ASTM International. ASTM C109/C109M-16a, Standard Test Method for Compressive Strength of Hydraulic Cement Mortars; ASTM International: West Conshohocken, PA, USA, 2016.

41. ASTM International. ASTM C348-18, Standard Test Method for Flexural Strength of Hydraulic-Cement Mortars; ASTM International: West Conshohocken, PA, USA, 2018.

42. ASTM International. ASTM D2936-20, Standard Test Method for Direct Tensile Strength of Intact Rock Core Specimens; ASTM International: West Conshohocken, PA, USA, 2020.

43. ASTM International. ASTM C596-18, Standard Test Method for Drying Shrinkage of Mortar Containing Hydraulic Cement; ASTM International: West Conshohocken, PA, USA, 2018.

44. ASTM International. ASTM C469/C469M-14, Standard Test Method for Static Modulus of Elasticity and Poisson's Ratio of Concrete in Compression; ASTM International: West Conshohocken, PA, USA, 2014.

45. ASTM International. ASTM C1723-16, Standard Guide for Examination of Hardened Concrete Using Scanning Electron Microscopy; ASTM International: West Conshohocken, PA, USA, 2016.

46. ASTM International. ASTM D4404-18, Standard Test Method for Determination of Pore Volume and Pore Volume Distribution of Soil and Rock by Mercury Intrusion Porosimetry; ASTM International: West Conshohocken, PA, USA, 2018. 
47. Jo, B.W.; Kim, C.H.; Tae, G.H.; Park, J.B. Characteristics of Cement Mortar with Nano-SiO 2 Particles. Constr. Build. Mater. 2007, 21, 1351-1355. [CrossRef]

48. Ji, T. Preliminary Study on The Water Permeability and Microstructure of Concrete Incorporating Nano-SiO $\mathrm{N}_{2}$. Cem. Concr. Res. 2005, 35, 1943-1947. [CrossRef]

49. Yilmaz, A.; Degirmenci, N. Possibility of Using Waste Tire Rubber and Fly Ash with Portland Cement as Construction Materials. Waste Manag. 2009, 29, 1541-1546. [CrossRef] [PubMed]

50. Mohammed, B.; Hossain, K.M.A.; Swee, J.T.E.; Wong, G.; Abdullahi, M. Properties of Crumb Rubber Hollow Concrete Block. J. Clean. Prod. 2012, 23, 57-67. [CrossRef]

51. Liu, H.; Wang, X.; Jiao, Y.; Sha, T. Experimental Investigation of the Mechanical and Durability Properties of Crumb Rubber Concrete. Materials 2016, 9, 172. [CrossRef] [PubMed]

52. Miller, N.M.; Tehrani, F.M. Mechanical Properties of Rubberized Lightweight Aggregate Concrete. Constr. Build. Mater. 2017, 147, 264-271. [CrossRef]

53. Green, B.H. Development of a High-Density Cementitious Rock-Matching Grout using Nano-Particles. Int. Concr. Abstr. Portal 2008, 254, 121-132.

54. Ltifi, M.; Guefrech, A.; Mounanga, P.; Khelidj, A. Experimental Study of the Effect of Addition of Nano-Silica. Procedia Eng. 2011, 10, 900-905. [CrossRef]

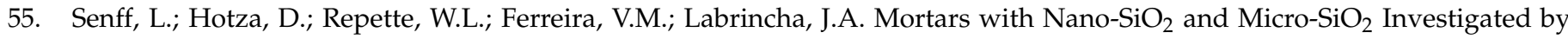
Experimental Design. Constr. Build. Mater. 2010, 24, 1432-1437. [CrossRef]

56. Sobolev, K.; Flores, I.; Hermosillo, R.; Torres-Martínez, L.M. Nanomaterials and Nanotechnology for High-Performance Cement Composites. In Nanotechnology of Concrete: Recent Developments and Future Perspectives; ACI International: Los Angeles, CA, USA, 2006.

57. Farzadnia, N.; Noorvand, H.; Yasin, A.M.; Aziz, F.N.A. The Effect of Nano Silica on Short Term Drying Shrinkage of POFA Cement Mortars. Constr. Build. Mater. 2015, 95, 636-646. [CrossRef]

58. Neto, A.A.M.; Cincotto, M.A.; Repette, W. Drying and Autogenous Shrinkage of Pastes and Mortars with Activated Slag Cement. Cement and Concrete Research. 2008, 38, 565-574. [CrossRef]

59. Li, H.; Xiao, H.-G.; Yuan, J.; Ou, J. Microstructure of Cement Mortar with Nano-Particles. Compos. Part B Eng. 2004, 35, 185-189. [CrossRef]

60. Sideris, K.; Manita, P. Estimation of Ultimate Modulus of Elasticity and Poisson Ratio of Normal Concrete. Cem. Concr. Compos. 2004, 26, 623-631. [CrossRef]

61. Sideris, K.K. Graphical Estimation of The Concrete Compressive Strength at Older Ages ( $>7$ days) On the Basis of the Concrete Strength Values Measured at The Early Ages of Hydration. In Modern Concrete Materials: Binders, Additions and Admixtures; Thomas Telford Publishing: London, UK, 2015; pp. 39-48.

62. Baalbaki, W.; Benmokrane, B.; Chaallal, O.; Aitcin, P.C. Influence of Coarse Aggregate on Elastic Properties of High-Performance Concrete. Mater. J. 1991, 88, 499-503.

63. Mukharjee, B.B.; Barai, S.V. Influence of Nano-Silica on the Properties of Recycled Aggregate Concrete. Constr. Build. Mater. 2014, 55, 29-37. [CrossRef]

64. Mohammed, B.S.; Khed, V.C.; Nuruddin, M.F. Rubbercrete Mixture Optimization Using Response Surface Methodology. J. Clean. Prod. 2018, 171, 1605-1621. [CrossRef]

65. Hunag, L.-J.; Wang, H.-Y.; Wang, S.-Y. A study of The Durability of Recycled Green Building Materials in Lightweight Aggregate Concrete. Constr. Build. Mater. 2015, 96, 353-359. [CrossRef]

66. Su, H.; Yang, J.; Ling, T.-C.; Ghataora, G.S.; Dirar, S. Properties of Concrete Prepared with Waste Tyre Rubber Particles of Uniform and Varying Sizes. J. Clean. Prod. 2015, 91, 288-296. [CrossRef]

67. Mohammed, B.S.; Liew, M.S.; Alaloul, W.S.; Khed, V.C.; Hoong, C.Y.; Adamu, M. Properties of Nano-Silica Modified Pervious Concrete. Case Stud. Constr. Mater. 2018, 8, 409-422. [CrossRef]

68. Faez, A.; Sayari, A.; Manie, S. Mechanical and Rheological Properties of Self-Compacting Concrete Containing $\mathrm{Al}_{2} \mathrm{O}_{3} \mathrm{Nanoparti-}^{-}$ cles and Silica Fume. Iran. J. Sci. Technol. Trans. Civ. Eng. 2020, 44, 217-227. [CrossRef]

69. Mohammed, B.S.; Achara, B.E.; Nuruddin, M.F.; Yaw, M.; Zulkefli, M.Z. Properties of Nano-Silica-Modified Self-Compacting Engineered Cementitious Composites. J. Clean. Prod. 2017, 162, 1225-1238. [CrossRef]

70. Li, G.; Wang, Z.; Leung, C.K.; Tang, S.; Pan, J.; Huang, W.; Chen, E. Properties of Rubberized Concrete Modified by Using Silane Coupling Agent and Carboxylated SBR. J. Clean. Prod. 2015, 112, 797-807. [CrossRef]

71. Du, H.; Du, S.; Liu, X. Durability Performances of Concrete with Nano-Silica. Constr. Build. Mater. 2014, 73, 705-712. [CrossRef]

72. Mohammed, B.S.; Adamu, M. Mechanical Performance of Roller Compacted Concrete Pavement Containing Crumb Rubber and Nano Silica. Constr. Build. Mater. 2018, 159, 234-251. [CrossRef]

73. Mohammed, B.S.; Azmi, N.J. Strength Reduction Factors for Structural Rubbercrete. Front. Struct. Civ. Eng. 2014, 8, 270-281. [CrossRef]

74. Mohammed, B.S.; Awang, A.B.; Wong, S.S.; Nhavene, C.P. Properties of Nano Silica Modified Rubbercrete. J. Clean. Prod. 2016, 119, 66-75. [CrossRef] 